\title{
HESSD
}

\section{Calibration approaches of cosmic-ray neutron sensing for soil moisture measurement in cropped fields}

\author{
C. A. Rivera Villarreyes, G. Baroni, and S. E. Oswald
}

Institute of Earth and Environmental Science, University of Potsdam, Karl-Liebknecht-Strasse 24-25, 14476 Potsdam, Germany

Received: 15 March 2013 - Accepted: 22 March 2013 - Published: 4 April 2013

Correspondence to: C. A. Rivera Villarreyes (crivera@uni-potsdam.de)

Published by Copernicus Publications on behalf of the European Geosciences Union.

Soil moisture measurement in cropped fields

C. A. Rivera Villarreyes et al.

Title Page

Abstract Introduction

Conclusions References

Tables Figures

14

$\triangleleft$

Back

Full Screen / Esc

Printer-friendly Version

Interactive Discussion 


\section{Abstract}

Measurement of soil moisture at the plot or hill-slope scale is an important link between local vadose-zone hydrology and catchment hydrology. This study evaluates the applicability of the cosmic-ray neutron sensing for soil moisture in cropped fields.

Measurements of cosmic-ray neutrons (fast neutrons) were performed at a lowland farmland in Bornim (Brandenburg, Germany) cropped with sunflower and winter rye. Three field calibration approaches and four different ways of integration the soil moisture profile to an integral value for cosmic-ray neutron sensing were evaluated in this study. The cosmic-ray sensing (CRS) probe was calibrated against a network of classical point-scale soil moisture measurements. A large CRS parameter variability was observed by choosing calibration periods within the different growing stages of sunflower and winter rye. Therefore, it was not possible to identify a single set of parameters perfectly estimating soil moisture for both sunflower and winter rye periods. On the other hand, CRS signal and its parameter variability could be understood by some crop characteristics and by predicting the attenuated neutrons by crop presence.

This study proves the potentiality of the cosmic-ray neutron sensing at the field scale; however, its calibration needs to be adapted for seasonal vegetation in cropped fields.

\section{Introduction}

The understanding of soil moisture variability across spatial-temporal scales is of great interest for several important aspects such as flood prediction and forecasting (Brocca et al., 2010; Koster et al., 2010; Steenbergen and Willems, 2012), weather prediction (Albergel et al., 2010), climate modeling (Team et al., 2004), agriculture management (Champagne et al., 2011; Vico and Porporato, 2011), and groundwater recharge (Patterson and Bekele, 2011).

25 Despite the important role of soil moisture in the hydrological cycle (for example, Porporato and Rodriguez-Iturbe (2002), Robinson et al. (2008) and Vereecken
HESSD

$10,4237-4274,2013$

Soil moisture

measurement in

cropped fields

C. A. Rivera Villarreyes

et al.

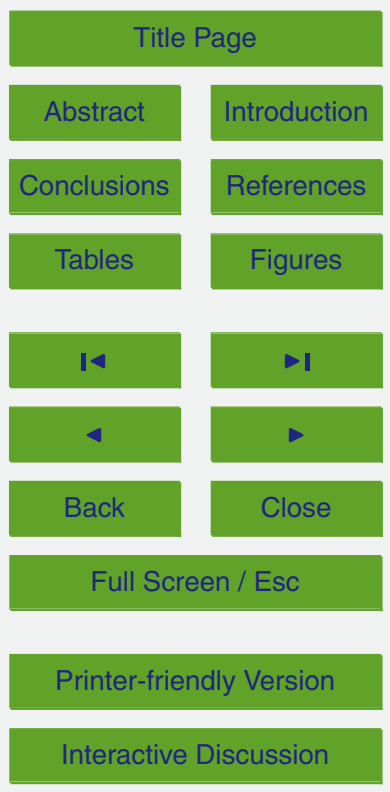


et al. (2008), among others), there is still a gap of current measurement capabilities to be covered between point-scale and large-scale remote sensing (Tapley et al., 2004; Entekhabi et al., 2010). Especially at the intermediate scale (e.g. small catchment scale, agricultural-field scale, etc.), measurement techniques for soil moisture are 5 still under development. Indeed, many methodologies of soil moisture measurements at this intermediate scale are investigated such as wireless soil moisture monitoring networks (Bogena et al., 2010), spatial TDR network (Graeff et al., 2010), groundpenetrating radar (GPR) measurements (Huisman et al., 2003), electrical resistivity tomography (ERT) measurements (Garre et al., 2011), time-lapse gravity data (Chris10 tiansen et al., 2011) and ground-based microwave radiometry (Schwank et al., 2009). Recently, integral quantifications of seasonal soil moisture in the root zone at the scale of a field, a small watershed or a hydrologic response unit have become possible with a novel methodology introduced by Zreda et al. (2008) and Desilets et al. (2010) named cosmic-ray sensing. The first steps of this methodology were initially presented 15 in a case study of Kodama (1984) in which estimations, both snow water equivalent and below-ground soil moisture, were indirectly derived by measuring "albedo neutrons", secondary products of cosmic radiation. More recently, based on using neutron transport simulations and field measurements in a grassland, Zreda et al. (2008) and Desilets et al. (2010) presented the first reliable measurements of soil moisture by counting natural aboveground fast neutrons. This methodology is now being implemented routinely in the Cosmic-ray Soil Moisture Observing System (COSMOS, Zreda et al., 2012). It is worth mentioning that cosmic-ray sensing (Zreda et al., 2008, Desilets et al., 2010; Franz et al., 2012a, b, 2013) and ground albedo neutron sensing (Kodama et al., 1980, 1985; Rivera Villarreyes et al., 2011) are the same methodology. In this study, we use the term cosmic-ray neutron sensing, which describes better the physical basics.

Indeed, the cosmic-ray neutron sensing shows a lot of potential for covering data requirements for large-scale studies, e.g. calibration and validation of land surface models and satellite-based soil moisture retrievals. Additionally, these data will improve

HESSD

$10,4237-4274,2013$

Soil moisture measurement in cropped fields

C. A. Rivera Villarreyes et al.

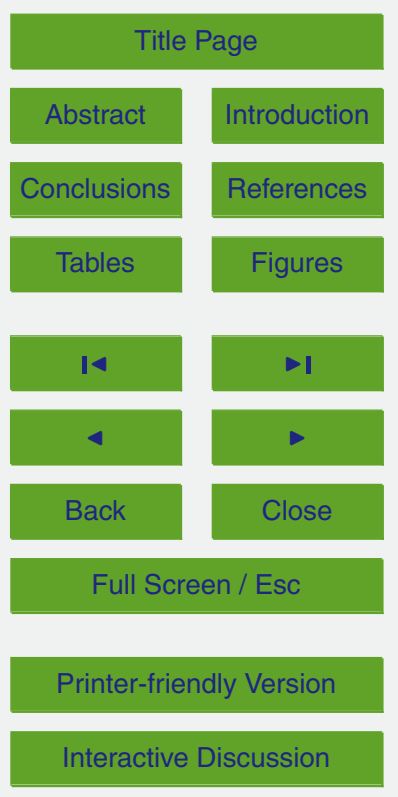

4239 
existing worldwide initiatives of soil moisture monitoring such as the International Soil Moisture Network (ISMN; Dorigo et al., 2011). However, there are still some open questions on this methodology that have to be evaluated with further research, such as field verification of measurement volume (vertical penetration depth and horizontal footprint) 5 in complex topographies (i.e. hill slopes); field verification of influence from other water environmental compartments (e.g. interception water, bounded water, biomass water, ponded water, etc.) to the soil moisture estimations, meaning possible correction factors; calibration approach without use of complex neutron transport models; transferability of calibration parameters to other times and locations; etc.

10 Based on the open questions mentioned above, our work is motivated and designed to cover the following main objectives:

- to investigate different field calibration approaches for the cosmic-ray neutron sensing;

- to observe the variation of calibration parameters throughout the crop-growing season;

- and to extend knowledge of the cosmic-ray neutron sensing to different crops.

\section{Materials and methods}

\subsection{Experimental site and monitoring activities}

Fast neutron measurements were carried out at a lowland farmland in Bornim (Brandenburg, Germany). The experimental site consisted of a 30 ha agricultural cropped field and is located close to Potsdam, and $30 \mathrm{~km}$ west of Berlin. Soil is mostly homogeneous with a dominant soil classification of loamy sand (USDA classification). At the same location, Rivera Villarreyes et al. (2011) applied the cosmic-ray neutron sensing method when the field was cropped with corn (Zea mays) in 2010.
HESSD

$10,4237-4274,2013$

Soil moisture measurement in cropped fields

C. A. Rivera Villarreyes et al.

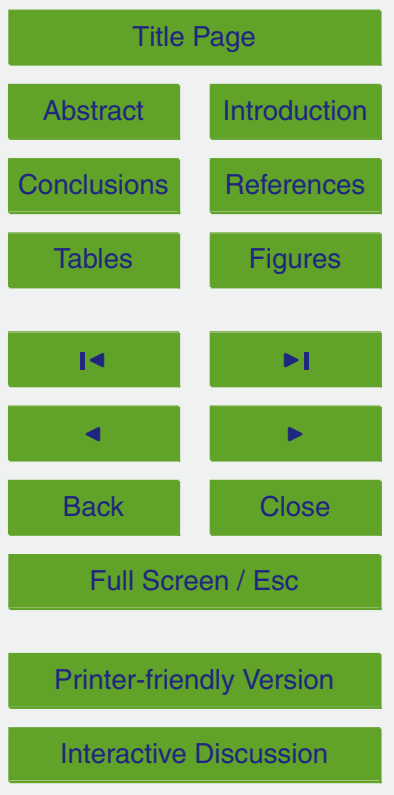


The first monitoring period in this study consisted of the entire growing season of sunflower (Helianthus annuus) from 5 May 2011 (initial stage) until 5 September 2011 (harvest). Later field activities and monitoring were restarted from 11 November 2011 until 25 May 2012 (shortly before harvest), now cropped with winter rye (Secale ce5 reale). We call these the sunflower period and the winter rye period. Because this study is focused on soil moisture estimations, we do not present data during winter period 2011-2012 when soil was frozen and sometimes there was snow.

During the sunflower and winter rye periods, a cosmic-ray soil moisture neutron sensor (CRS-1000, Hydroinnova, Albuquerque, USA), named here with the abbre10 viation $\mathrm{CRS}$ probe, was installed. The probe contained two proportional counters, one counter surrounded by a low-density polyethylene (for fast neutrons) and a second, bare counter (for thermal neutrons) installed in the center of the field $\left(52.431^{\circ} \mathrm{N}\right.$, $13.021^{\circ} \mathrm{E}$, WGS84, $84 \mathrm{~m}$ a.s.I.) named "A" in Fig. 1. Additionally, the sensor in location A coincided with a monitoring location in Rivera Villarreyes et al. (2011), since one ob15 jective of this study is to verify calibration parameters previously estimated during the corn period. The sensor was mounted on a pole at a height of $1.5 \mathrm{~m}$ above ground. The neutron-pulse-counting modules of the CRS probe were set up to record counts every 20 min; neutron counts were subsequently integrated into the one-hour time intervals in data processing. It is well known that CRS uncertainty decreases in low altitudes, 20 such as the Bornim site. However, since our calibration approach is based on a longer period (> 30 days, cf. 2.3), we expected that this natural uncertainty is not relevant for calibration.

In this study, twelve FDR (Frequency Domain Reflectometry MR2 probes, DeltaT Devices Ltd., Cambridge, UK) sensors were distributed in Bornim farmland in five locations (A-E in Fig. 1) and three depths (5, 20 and $40 \mathrm{~cm}$ ). All the five locations had sensors at 5 and $20 \mathrm{~cm}$ depth, but only the locations labeled "B" and "D" had additional devices at $40 \mathrm{~cm}$ depth. The location of the deepest sensor was defined according to predictions of CRS penetration depth (Eq. 1) based on the observed level of soil moisture from 2010. Additionally, soil texture measurements do not change significantly
HESSD

10, 4237-4274, 2013

Soil moisture

measurement in

cropped fields

C. A. Rivera Villarreyes

et al.

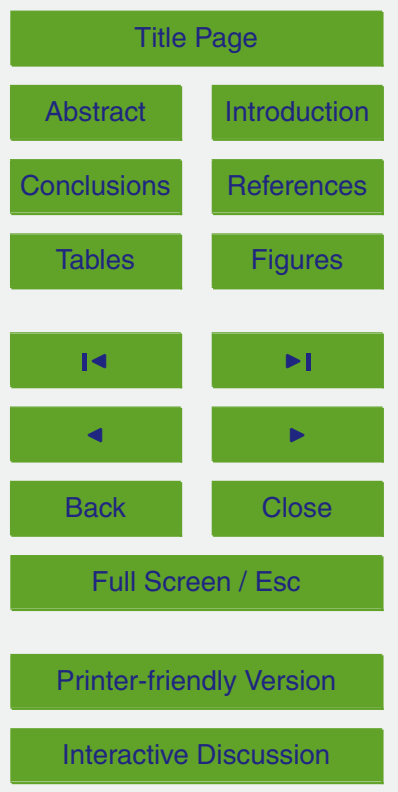


in the first $50 \mathrm{~cm}$ soil layer (cf. Sect. 3.1). Before installation of FDR sensors, soil cores were extracted at same locations in order to verify FDR field calibration in both periods (sunflower and winter rye).

The FDR probes were used to measure soil moisture every $20 \mathrm{~min}$. Subsequently, 5 FDR soil moisture was averaged to an hourly time step and used for the CRS calibration, as is explained in following sections. A field calibration from our previous study (Rivera Villarreyes et al., 2011) was used for FDR sensors.

During the sunflower and winter rye periods, measurements of crop heights were taken throughout the monitoring period with four replicates of crop height per day in 10 each monitoring location (A-E; see Fig. 1). This information was used to distinguish major crop-growing stages in the monitoring period. Moreover, literature data from the Food and Agriculture Organization (FAO) was used for comparison.

\subsection{Basis of the cosmic-ray neutron sensing}

Intermediate-energy neutrons called fast neutrons (1-2 MeV; Hess et al., 1961) are 15 created as the product of interactions (collisions) between secondary cosmic ray particles and land surface materials such as soil, snow, plant canopies, etc. These neutrons are randomly distributed below and above ground when they penetrate the soil, and later are scattered back into the air. The neutron energy level varies due to several collisions with soil nuclei. Some neutrons are absorbed completely, and others 20 can be modified completely or partially by kinetic losses. In these collisions, the hydrogen's nuclei play an important role due to its large neutron-moderation capabilities (elastic scattering cross section) compared to other common elements found in soil minerals (Zreda et al., 2008; Rivera Villarreyes et al., 2011). This is the principle which allows a passive and non-invasive estimation of soil moisture with the cosmic-ray neu25 tron sensing. The mathematical function between fast neutrons and soil moisture is presented in Table 1.

Horizontal spatial coverage of the CRS probe can be defined as the land surface region from which $86 \%$ of the counted fast neutrons originate. Zreda et al. (2008)

\section{HESSD}

$10,4237-4274,2013$

Soil moisture measurement in cropped fields

C. A. Rivera Villarreyes et al.

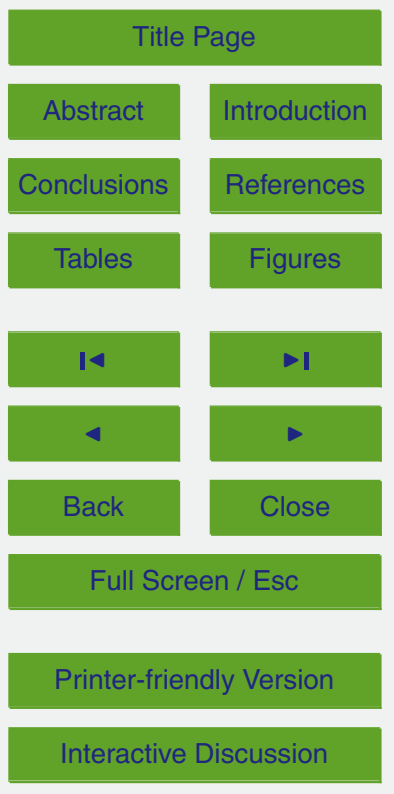


suggested adopting a value of ca. $600 \mathrm{~m}$ diameter. The depth of measurement of the CRS, called effective depth, depends on the mean free path length for elastic collisions in soil, which is on the scale of tens of centimeters. Soil moisture controls this sample depth because the probability of neutron scattering and absorption events depends 5 mainly on the number of hydrogen molecules. Very recently, Franz et al. (2012a) presented an equation based on the hydrogen contribution from the soil moisture profile and mineral water content (or lattice water) only, as follows:

$z^{*}=\frac{5.8}{\rho_{\mathrm{bd}} \tau+\theta+0.0829}$,

where $z^{*}$ is the effective depth of the CRS probe [cm], $\rho_{\mathrm{bd}}$ is the soil dry bulk density $10\left[\mathrm{~g} \mathrm{~cm}^{-3}\right], \tau$ is the weight fraction of lattice water in the mineral grains and bound water defined as the amount of water released at $1000^{\circ} \mathrm{C}$ preceded by drying at $105^{\circ} \mathrm{C}(\mathrm{g}$ of water per $\mathrm{g}$ of dry minerals, herein known as lattice water), and $C \theta$ is the volumetric pore water content $\left[\mathrm{m}^{3} \mathrm{~m}^{-3}\right]$.

\subsection{Calibration of the CRS probe}

\subsubsection{Corrections}

Prior to the calibration of the CRS probe, fast neutrons were corrected by changes of local atmospheric pressure (Rivera Villarreyes et al., 2011), incoming cosmic radiation (Zreda et al., 2012) and atmospheric water vapor (Franz et al., 2012b). In the case of incoming cosmic rays, the neutron monitoring station Jungfraujoch in Switzerland (www.nmdb.eu) was set up as a reference station. When the neutrons in Jungfraujoch were different than the mean historical value of 179.71 counts $^{-1}$, we assumed that incoming cosmic rays in Bornim also changed proportionally.

\section{HESSD}

$10,4237-4274,2013$

Soil moisture

measurement in

cropped fields

C. A. Rivera Villarreyes

et al.

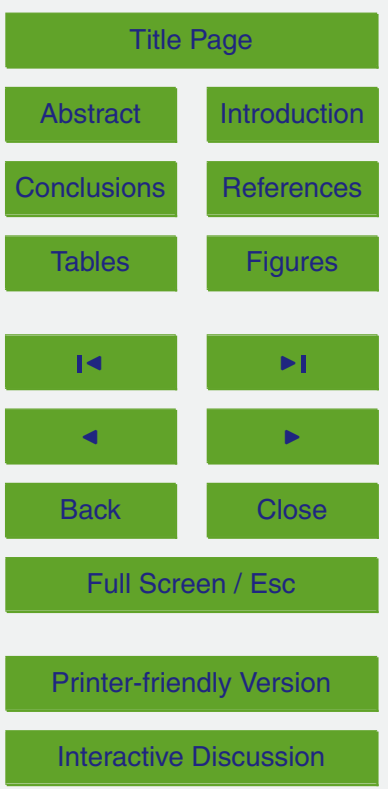




\subsubsection{Calibration approaches}

The calibration methodology is still a very important open question. On the one hand, cosmic-ray neutron sensing was calibrated with Monte Carlo neutron transport simulations (Desilets et al., 2010). In the equation proposed for relating soil moisture and

5 fast neutrons (Table 1, Eq. 1), variables $a_{0}, a_{1}$ and $a_{2}$ are defined as calibration parameters and parameter $N_{0}$ as a reference neutron count over dry soil conditions. In the following, Rivera Villarreyes et al. (2011) successfully calibrated the probe modifying $a_{0}, a_{1}$ and $a_{2}$ for a corn field and showed how those have to be adapted when using different values of $N_{0}$. Moreover, Franz et al. (2012b) presented a calibration procedure fitting directly a value $N_{0}$ in a field with $24 \%$ slow-changing vegetation cover, primarily composed of creosotebush (Larrea tridentate), grasses, forbes, catci, and mesquite. In order to explore the different methodologies and identify better approaches, we used three different approaches to calibrate the CRS probe: (i) a fully empirical approach altering $a_{0}, a_{1}$ and $a_{2}$ freely, (ii) a semi-empirical approach where $a_{0}, a_{1}$ and $a_{2}$ are relatively modified with respect to the parameter of Desilets (2010), and (iii) a $N_{0}$-calibration approach according to Franz et al. (2012b) and Zreda et al. (2012). All mathematical relations for these approaches are presented in Table 1. The semi-empirical approach considered the CRS calibration by multiplying the curve of soil moisture-neutrons by a constant (Hydroinnova, 2010). The $N_{0}$-calibration approach is slightly different from the one proposed in the literature, since an optimal single value of $N_{0}$ for the entire calibration period was chosen, instead of the $N_{0}$ calculated with soil moisture data from one-day (or six-hour) sampling campaigns. The calibration was done by minimizing the root mean square error (RMSE) between FDR and CRS with the non-linear least square (NLS) library in R language and environment. The goodness of fit in the calcomputed for the entire monitoring period, sunflower and winter rye.

Soil moisture measurement in cropped fields

C. A. Rivera Villarreyes et al.

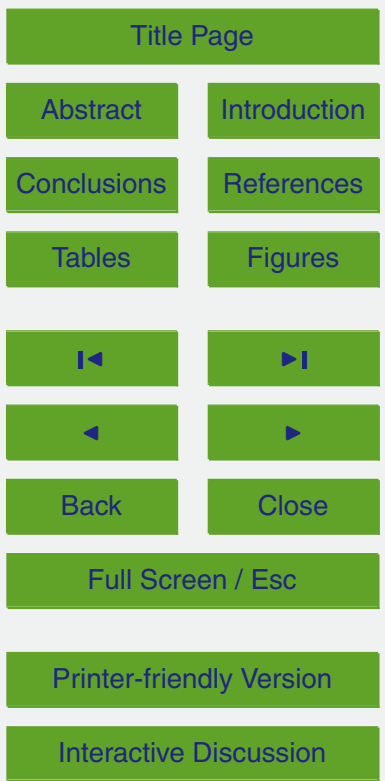




\subsubsection{Calibration scenarios: effect of CRS effective depth}

Recently, Franz et al. (2012a) presented an equation for estimation of the CRS penetration depth (Eq. 1), which was evaluated mostly in field without significantly observable changes of biomass. Therefore, we designed four calibration scenarios to verify the 5 role of the CRS penetration depth and the different ways to integrate reference soil moisture for the CRS calibration in depth in cropped fields (Fig. 2):

S1 constant penetration depth and equal neutron weights in depth,

S2 variable penetration depth and equal neutron weights in depth,

S3 constant penetration depth and variable neutron weights in depth, and

S4 variable penetration depth and variable neutron weights in depth.

In all scenarios the CRS values are taken to represent the soil water mass down to the effective penetration depth, with the given weighting with depth $z^{*}$.

In the case of constant penetration depth (scenario S1), the value of $z^{*}$ was set as $0.40 \mathrm{~m}$, which is about the mean value between the minimum $(12 \mathrm{~cm})$ and the maximum $(70 \mathrm{~cm})$ according to Desilets et al. (2010). Also, this depth was chosen for the installation of the deepest sensor in the field. The variable penetration depth for $\mathrm{S} 2$ was estimated based on Eq. (1).

Scenarios S3 and S4 consider neutrons from different depths to be contributing differently to the total count observed above ground (Eq. 3). This is because detected neutrons do not originate uniformly distributed in depth. In terms of neutron moderation, neutron intensity tends to decrease exponentially when they penetrate a certain material (Hassanein et al., 2005; Oswald et al., 2008). This exponential decrease is a function of the thickness and neutron scattering properties of the penetrating material, i.e. soil porous medium. Therefore, we adopt an exponential neutron weighting
HESSD

10, 4237-4274, 2013

Soil moisture measurement in cropped fields

C. A. Rivera Villarreyes et al.

Title Page
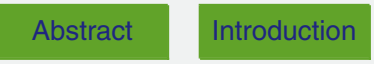

Conclusions

Tables Figures

14

4

Back

Close

Full Screen / Esc

Printer-friendly Version

Interactive Discussion $\alpha_{z}=e^{k \cdot z / z^{*}}$, 
where $\alpha_{z}$ is the weighting neutron factor $[-], z$ is the vertical depth [m], $z^{*}$ is the penetration depth or effective depth for the CRS probe [m], and $k$ is a negative constant which may depend on nuclear properties of the porous medium. In our case, $k$ values were calibrated from FDR soil moisture. Therefore, the soil moisture value weighted according to different neutron contributions in depth was defined as follows:

$\theta_{\mathrm{FDR}}^{\mathrm{av}}=\frac{\int_{0}^{z^{*}} \alpha_{z} \cdot \theta_{\mathrm{FDR}, z} \cdot \mathrm{d} z}{\int_{0}^{z^{*}} \alpha_{z} \cdot \mathrm{d} z}$,

where $\theta_{\mathrm{FDR}}^{\mathrm{av}}$ is the averaged FDR soil moisture used to calibrate for the CRS probe with the scenarios $\mathrm{S} 3$ and $\mathrm{S} 4\left[\mathrm{~m}^{3} \mathrm{~m}^{-3}\right], \theta_{\mathrm{FDR}, z}$ is the FDR volumetric soil moisture observed at depth $z\left[\mathrm{~m}^{3} \mathrm{~m}^{-3}\right]$, and $\alpha_{z}$ is the weighting factor at depth $z$. The effective depth, $z^{*}$, is constant for S3, but variable for S4. In this study, $z$ is only available at depths of $5 \mathrm{~cm}$, $20 \mathrm{~cm}$, and $40 \mathrm{~cm}$. The definite integral in Eq. (3) was approximated by the trapezoid rule.

In all the scenarios, special weighting was not applied in the horizontal direction. Our assumption is justified in the very homogeneous soil conditions in Bornim (see discussion later). Moreover, others studies (Franz et al., 2012a, b, 2013; Zreda et al., 2012) have provided successful calibration with this assumption, even in more heterogeneous fields than Bornim.

\subsubsection{Effect of calibration periods and duration}

Calibration parameters of the CRS probe were derived using field data of soil moisture 20 from the FDR network. Here, we focus on the understanding of how soil moisture estimation and calibration parameters change if they are calibrated with soil moisture data from different crop-growing stages. Thus, the entire monitoring period (cf. Sect. 2.1)
HESSD

10, 4237-4274, 2013

Soil moisture

measurement in

cropped fields

C. A. Rivera Villarreyes

et al.

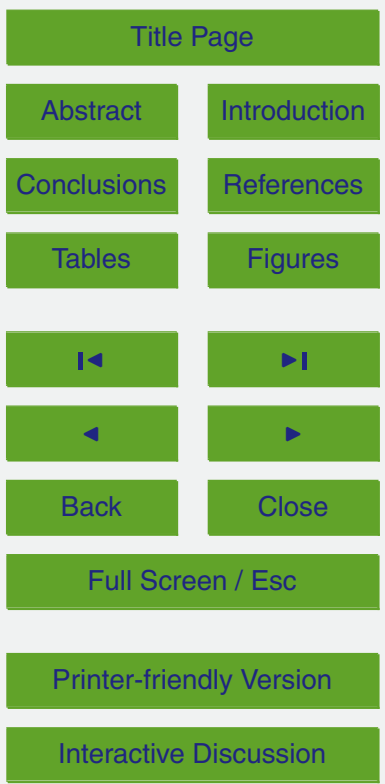


was split into six consecutive short periods (D1 to D6, Table 2). Crop heights and FAO recommendations were used as a proxy to identify these periods. In the case of sunflower, calibration periods D1-D4 have approximately equal length, coinciding with the main growing stages of sunflower. In winter rye, mid-season and late stage extended 5 approximately to 40 and 30 days, respectively. The objective of this subdivision was to determine if the crop stage leads to a different set of calibration parameters.

\section{Results and discussion}

\subsection{Spatial variability of soil texture and soil moisture within CRS footprint}

Surface soil texture was measured in our previous study (Rivera Villarreyes et al., 2011) 10 in 16 locations (asterisk marks in Fig. 1). Additionally, soil samples were taken in the five FDR locations at 5, 10, 20, 30 and $40 \mathrm{~cm}$ depths (Fig. 1). Results revealed that soil texture is very homogenous at the Bornim site, classified as loamy sand, with a high sand content up to $83 \%$. Moreover, soil texture was observed to change slightly below $50 \mathrm{~cm}$ depth in two profiles dug up to $150 \mathrm{~cm}$ depth in locations B and D. From texvolume of the CRS probe.

In terms of soil moisture, we analyzed old time series of near-surface FDR values during the corn period in 2010 (Rivera Villarreyes et al., 2011). The idea was to verify whether five selected locations for the FDR network in the current study (Fig. 1) are representative in respect to 19 FDR locations previously evaluated in the corn period. The RMSE and $r^{2}$ between time series of mean FDR soil moisture with 19 and 5 locations were $0.018 \mathrm{~m}^{3} \mathrm{~m}^{-3}$ and 0.952 , respectively, concluding that these five locations are a good simplification of the former FDR network.

The representativeness of five FDR locations selected for this study was also verified each location) within the CRS footprint (Fig. 1). A histogram of soil moisture showed

HESSD

$10,4237-4274,2013$

Soil moisture

measurement in

cropped fields

C. A. Rivera Villarreyes

et al.

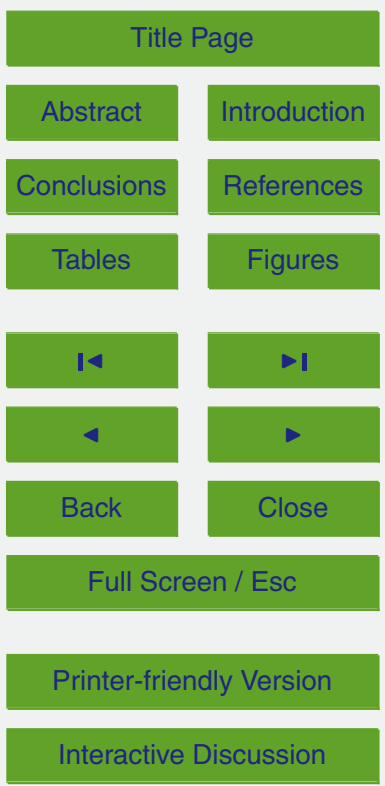


a perfectly normal distribution (data not shown) with standard deviations of 0.014 and $0.021 \mathrm{~m}^{3} \mathrm{~m}^{-3}$ for the two campaigns, respectively. In the two campaigns, mean soil moisture was 0.053 and $0.14 \mathrm{~m}^{3} \mathrm{~m}^{-3}$. These values were well comparable to mean values from the five-FDR network, $0.064 \pm 0.006 \mathrm{~m}^{3} \mathrm{~m}^{-3}$ and $0.175 \pm 0.016 \mathrm{~m}^{3} \mathrm{~m}^{-3}$, re-

5 spectively. Therefore, the selected locations for the FDR network in this study ( $A-E$ in Fig. 1) are considered a good representation of the mean soil moisture at the field based on (i) the assumption that soil moisture variability is higher at $5 \mathrm{~cm}$ depth compared to deeper locations (e.g. Choi and Jacobs, 2007, among others) and (ii) observations of homogenous soil texture in both vertical and horizontal directions. Finally, this FDR network was used as ground truth in order to calibrate the CRS probe.

Additionally, the previous field calibration (Rivera Villarreyes et al., 2011) was verified with new soil samples taken prior to installation of FDR sensors in sunflower and winter rye periods. Gravimetric soil moisture and bulk density were measured from soil cores $\left(100 \mathrm{~cm}^{3}\right)$. Volumetric soil moisture from soil cores was calculated from gravi15 metric soil moisture multiplied by the mean bulk density $\left(\sim 1.40 \mathrm{~g} \mathrm{~cm}^{-3}\right)$. Subsequently, volumetric field soil moisture was compared to the FDR calibration (Rivera Villarreyes et al., 2011). The RMSE between measured soil moisture and FDR estimations was ca. $0.04 \mathrm{~m}^{3} \mathrm{~m}^{-3}$.

\subsection{Neutron corrections}

20 The standard neutron correction due to changes of atmospheric pressure from the cosmic-ray neutron detector was applied in both monitoring periods. Neutrons at the Jungfraujoch station showed a decreased tendency (from 0 to $10.7 \%$ ) of the incoming high-energy cosmic rays (data not shown) during the monitoring period. Therefore, corrections were needed. In the case of corrections due to atmospheric water vapor, 25 local variations were smaller and the correction factor was calculated as ca. 0.999 throughout the monitoring periods. The final range of corrected fast neutrons used for the CRS probe calibration varied from $668 \pm 26$ to $1330 \pm 36$ counts per hour.

HESSD

10, 4237-4274, 2013

Soil moisture measurement in cropped fields

C. A. Rivera Villarreyes et al.

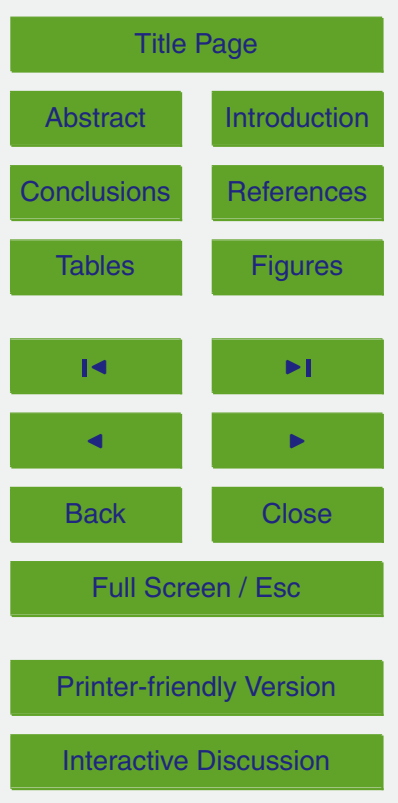




\subsection{Comparison of calibration approaches}

Calibration parameters derived in the same field previously cropped with corn in 2010 (Rivera Villarreyes et al., 2011) provided a large overestimation of soil moisture (RMSE $=0.20 \mathrm{~m}^{-3} \mathrm{~m}^{-3}$ ). The cause of this large discrepancy may be attributed to the 5 CRS penetration depth. In the previous study, the working assumption was that CRS penetration depth is comparable to FDR sensors located at $5 \mathrm{~cm}$ depth under wet periods only. However, the recently introduced Franz' equation (2012a) for the CRS penetration depth suggested that minimum values could be up to $20 \mathrm{~cm}$ depth in respect to this previous study.

10 Therefore, in the current study we evaluated four calibration scenarios to account for depth information in three calibration approaches named fully empirical, semi-empirical and $N_{0}$-calibration (Tables 1, A1, A2 and A3). Overall, calibration approaches fitting either $f_{\text {cal }}$ or $N_{0}$ (Table A1) provided the maximum values of RMSE between the FDR network and CRS probe, compared to the approach fitting $a_{0}, a_{1}$, and $a_{2}$. The mean values of RMSE $(n=24)$ obtained are $0.026,0.032$ and $0.044 \mathrm{~m}^{3} \mathrm{~m}^{-3}$ for the fully empirical, semi-empirical and $N_{0}$-calibration approaches, respectively. The statistical significance of the calibration results was tested with an analysis of variance (ANOVA; Driscoll, 1996) test and a Student's $t$ test (Hedderich and Sachs, 2012). In the case of ANOVA, the null hypothesis was defined as $H_{0}: \mu_{\text {Fully }}=\mu_{\text {Semi }}=\mu_{N_{0}}$, where $\mu_{\text {Fully }}, \mu_{\text {Semi }}$, and $\mu_{N_{0}}$ represent the mean RMSE for the three calibration approaches; the alternative hypothesis was set as "at least one of the RMSEs is different". The ANOVA test indicated the rejection of the null hypothesis at the 0.05 significance level. Additionally, a one-by-one comparison of the RMSE mean values with the Student's $t$ test was set up with null hypotheses as $H_{0}: \mu_{\text {Fully }}=\mu_{\text {Semi }}, H_{0}: \mu_{\text {Semi }}=\mu_{N_{0}}$ and $H_{0}: \mu_{\text {Fully }}=\mu_{N_{0}}$. From the Student's $t$ test, we observed a difference between the three calibration approaches at the 0.05 significant level. Therefore, minimum RMSE $=0.026 \pm 0.008 \mathrm{~m}^{3} \mathrm{~m}^{-3}$ for the fully empirical approach compared to the other two approaches is statistically significant. From the calibration results, we observed that the calibration approach fitting three
HESSD

$10,4237-4274,2013$

Soil moisture measurement in cropped fields

C. A. Rivera Villarreyes et al.

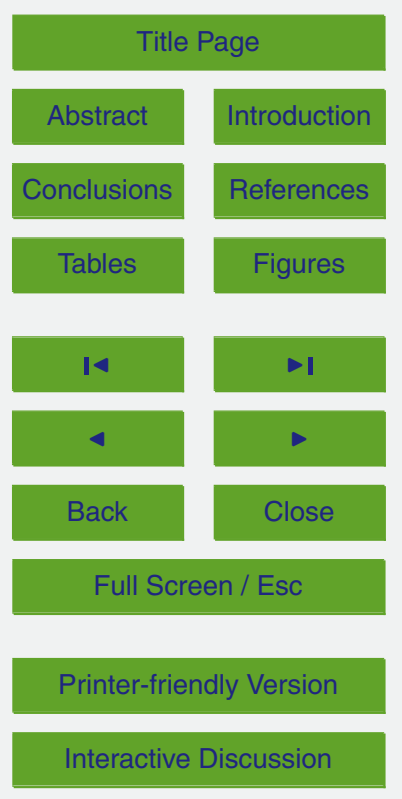


parameters, as expected, improves significantly the soil moisture performance. However, it will usually require more calibration data compared to single-parameter fitting approaches.

\subsection{Improvement of CRS soil moisture with calibration scenarios}

5 The improvement of CRS soil moisture with the increase of scenario complexity is not so evident (Fig. 4). Based on the ANOVA test with null hypothesis set as $H_{0}: \mu_{\mathrm{S} 1}=$ $\mu_{\mathrm{S} 2}=\mu_{\mathrm{S} 3}=\mu_{\mathrm{S} 4}$, where $\mu_{\mathrm{S} 1}, \mu_{\mathrm{S} 2}, \mu_{\mathrm{S} 3}$ and $\mu_{\mathrm{S} 4}$ are the RMSE for scenarios $\mathrm{S} 1, \mathrm{~S} 2, \mathrm{~S} 3$, and S4, the estimated $F$ value (F-Statistics; Silvapulle, 1996) could not reject the null hypothesis at the 0.05 significance level. Therefore, we conclude that four calibration scenarios do not present a statistical difference.

The effective depth for scenarios S2 and S4 ranged between 18 and $45 \mathrm{~cm}$ with the assumptions of $\tau=0$. Introducing the measured value of lattice water $\tau=0.012 \mathrm{~m}^{3} \mathrm{~m}^{-3}$, penetration depth decreased up to $40 \mathrm{~cm}$ in dry periods. This value of lattice water is the mean from five FDR locations at 5, 20 and $40 \mathrm{~cm}$ depths. The real penetration depth may be slightly less than the range estimated here due to influence of other hydrogen pools not considered, for example organic matter $(<2 \%$; Gebbers et al., 2009) and biomass. From all calibration datasets and calibration approaches $(n=18)$, scenario with constant effective depth $\left(\mathrm{RMSE}=0.035 \pm 0.012 \mathrm{~m}^{3} \mathrm{~m}^{-3}\right)$ and variable effective depth (RMSE $=0.034 \pm 0.014 \mathrm{~m}^{3} \mathrm{~m}^{-3}$ ) do not provide a statistical difference at the 0.05 significant level based on Student's $t$ test. Therefore, the assumption of constant penetration $\left(z^{*}=40 \mathrm{~cm}\right)$ of the CRS probe is acceptable for our field conditions with a homogenous soil profile at the first $50 \mathrm{~cm}$ soil layer.

Moreover in the case of the fully empirical approach, the implementation of a neutron weighting function in depth showed no significant difference, with RMSE $=0.034 \pm$ tions are in agreement with Franz et al. (2012a) and Franz et al. (2012b), as the difference between these scenarios was not relevant to their study either. The fact that Franz et al. (2012a) and Franz et al. (2012b) evaluated a different neutron weighting 4250
HESSD

10, 4237-4274, 2013

Soil moisture measurement in cropped fields

C. A. Rivera Villarreyes et al.

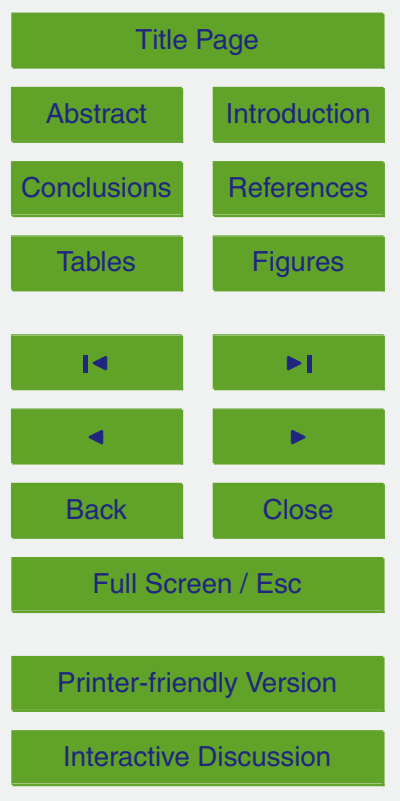


function (linear shape) than the exponential-decay form tested in this study suggests that a neutron weighting scheme in depth may indeed not alter calibration parameters.

\subsection{Crop influence on the cosmic-ray neutron sensing parameters}

From statistical analyses, we found a large variability of calibration performance (RMSE 5 increased from 0.029 to $0.045 \mathrm{~m}^{3} \mathrm{~m}^{-3}$ ) at the 0.05 significance level by choosing different calibration periods (D1-D6). This variability is more evident in the sunflower period than in the winter rye period from RMSE values (Fig. 3). This could be attributed to differences in soil moisture and crop characteristics during these two periods.

Due to the improvement of CRS soil moisture mostly depending on selection of the calibration period, we opted to investigate how calibration parameters varied throughout the growing season. In Fig. 4, optimal calibration parameters for each growing period (D1-D6) are presented for each calibration approach. For the fully empirical approach only parameter $a_{0}$ is shown. Parameters $a_{1}$ and $a_{2}$ show a similar behavior and, therefore, are only reported in the appendix. As was explained in Sect. 3.4,

15 Fig. 4 shows also that parameters do not vary substantially between calibration scenarios. Also, parameter tendency differed for sunflower and winter rye, e.g. parameters $a_{0}$ and $f_{\text {cal }}$ at the mid-season and late stage (Fig. 4). This may be due to different soil moisture levels observed in periods, length of growing periods and crop characteristics (Table 2). In the case of $N_{0}$ parameters in the sunflower period, these presented 20 an exponential-decay tendency from initial to mid-season of sunflower, followed by an increase of $N_{0}$ at the late sunflower season. Similar conclusions were drawn by Hornbuckle et al. (2012) with a decrease of $N_{0}$ according to the increase of corn biomass; in our case $N_{0}$ tendency was inversely proportional to sunflower height (Figs. 4 and 7). Moreover, we also observed the same hysteresis behavior with an increase of $N_{0}$ 25 at the end of the growing season (with expected decrease of sunflower biomass) as Hornbuckle et al. (2012). Parameter variability of $a_{0}, f_{\text {cal }}$ and $N_{0}$ was also computed at a daily time resolution throughout sunflower and winter rye periods (data not shown). The parameter variability in the long term (between growing stages) as shown in Fig. 4
$10,4237-4274,2013$

Soil moisture measurement in cropped fields

C. A. Rivera Villarreyes et al.

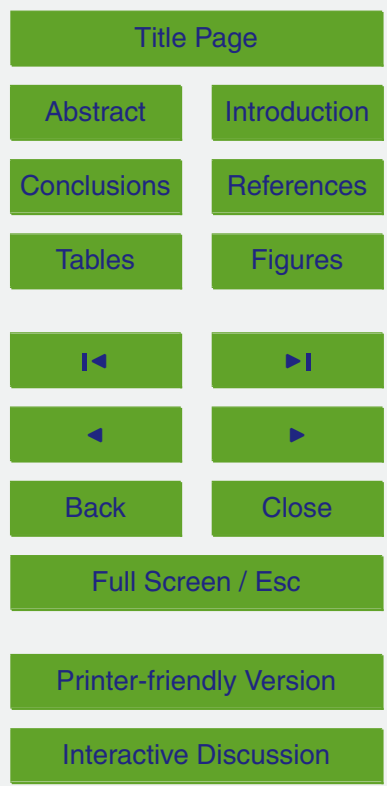


was significantly higher than the parameter variability within each growing period at the 0.05 statistical level. Therefore, the fact that the observations of Hornbuckle (2012) derived from single-day soil campaigns are comparable to our approach of selecting the entire growing period verified the methodology applied here.

\section{$5 \quad 3.6$ The CRS-derived soil moisture}

Calibration datasets for the mid-season of sunflower (D3) and for the late season of winter rye (D6) delivered similar CRS parameters (Table A1) and a minimum RMSE of $0.019 \mathrm{~m}^{3} \mathrm{~m}^{-3}$ with the fully empirical approach. Similarity in calibration results (D3 and D6) shows the consistency of the calibration approach and its independency 10 from the FDR setup. Moreover, RMSE is comparable to other studies such as Franz et al. (2012a) and Franz et al. (2012b). For simplification, calibration results of the D3 period are used in Fig. 5 and the following discussion. Additionally, soil moisture anomalies were computed for CRS and FDR. The anomalies were computed by subtracting the mean value from the times series and later dividing by the standard debergel et al., 2012, and references therein), soil moisture anomalies could be useful to compare observations of different measurement volumes, e.g. remote sensing versus ground observations.

In general, the fully empirical approach provided acceptable results of CRS soil mois20 ture in terms of dynamics (Fig. 5 lower) and absolute values (Fig. 5 middle) for sunflower and winter rye periods, beside its different measurement volume compared to the FDR network. However, there are some discrepancies observed in short time periods. For example in the drier period (May 2011) with few precipitation events and a decrease of soil moisture by evapotranspiration, the CRS probe underestimated the

FDR soil moisture. Here, calibration parameters (D3) consider already crop influence (i.e. biomass and other crop characteristics); therefore, they are prevented from precisely predicting values of soil moisture in the initial sunflower stage (low biomass). In wet periods of the sunflower season, the CRS is in agreement with precipitation events,

HESSD

10, 4237-4274, 2013

Soil moisture measurement in cropped fields

C. A. Rivera Villarreyes et al.

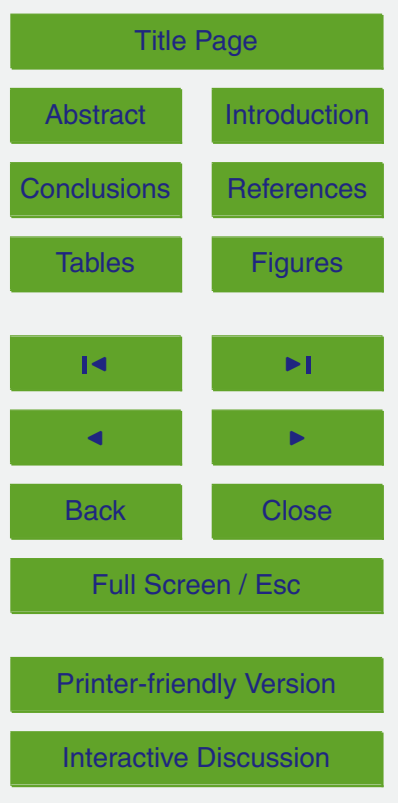


which is reflected by the good match to the peaks of FDR soil moisture (e.g. beginning and end of July 2011). On the other hand, the CRS probe sometimes underestimated FDR soil moisture during the infiltration process (e.g. 25 August 2011). Already Franz et al. (2012a) showed this hysteresis behavior of the CRS probe during periods of 5 infiltration, evaporation and drainage.

Calibrated CRS parameters performed acceptably during the winter rye period in terms of absolute values (Fig. 5 middle). From soil moisture anomalies (Fig. 5 lower), sometimes CRS showed a steeper decrease compared to the FDR network in the winter rye period, e.g. from middle to end of May 2012. In general, the mean CRS soil 10 moisture was higher than the mean FDR during the sunflower period. However, this CRS mean tendency was slightly smaller than the FDR mean tendency in the winter rye period.

Discrepancies between the CRS probe and FDR network during sunflower and winter rye periods are attributed to changes of $\mathrm{H}$ pools moderating fast neutrons. As has been observed, lattice water (Zreda et al., 2012), organic matter, biomass (Hornbuckle et al., 2012), atmospheric water vapor (Franz et al., 2012b), etc., could affect CRS signal. Measurement of lattice water showed values below $0.012 \mathrm{~m}^{3} \mathrm{~m}^{-3}$, expected for sandy soils; therefore its importance is not relevant in this study. Organic matter was measured below $2 \%$, in concordance with Gebbers et al. (2009), which may not contribute significantly to the neutron moderation. Therefore, major $\mathrm{H}$ moderations to fast neutrons are expected to come from soil moisture and crop, as discussed in the following section.

\subsection{Understanding the CRS signal in cropped fields}

Temporal variability of crop hydrogen pools throughout the season, as well spatial 25

variability within the crop aboveground biomass and root distribution, makes it more challenging to interpret the CRS signal in a cropped field. For example, fast neutron decreased throughout the sunflower season (at least until its maximum stage) from 918-1188 counts per hour (initial stage with $5 \mathrm{~cm}$ height) up to $682-970$ counts per

\section{HESSD}

$10,4237-4274,2013$

Soil moisture measurement in cropped fields

C. A. Rivera Villarreyes et al.

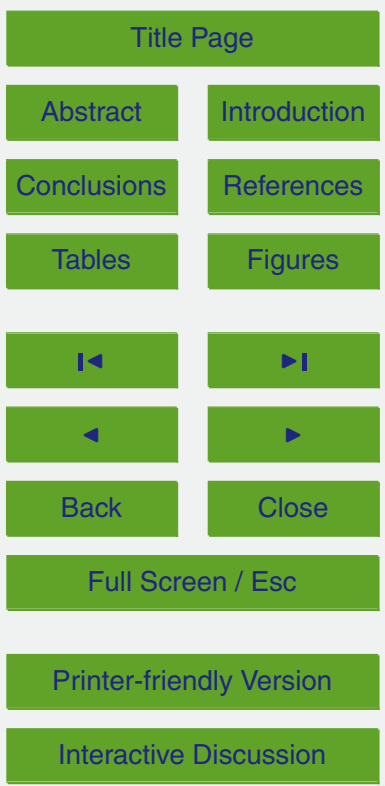


hour (middle season with maximum height of ca. $150 \mathrm{~cm}$ ). Thus, the relation between fast neutrons and soil moisture is not unique throughout the crop season. This behavior is shown in Fig. 6 with a scatter plot between soil moisture and relative neutrons. Here, the CRS calibration curve could be readjusted by adding or subtracting $5 \%(\mathrm{v} / \mathrm{v})$ 5 to account for temporal variability of crop properties affecting fast neutrons in the sunflower period. On the other hand, the calibration curve (D3) fitted well datasets for the mid-season (D5) and late season (D6) of winter rye. In these last two periods, neutron moderation may be similar to the D3 period of sunflower; here two crops present its maximum yield, maximum height, maximum water content, etc.

10 Calibration parameters differed throughout crop stages (cf. Sects. 3.3-3.5). Difference of CRS soil moisture by parameter differences is related to some time-variable crop characteristic. For instance, absolute mean difference between CRS soil moisture using D1 (low biomass and low root density) and D3 (high biomass and well-developed root structure) parameters $\left(\Delta \theta_{\text {crop }}\right)$ is well correlated to changes of crop height. This over, it seems that the CRS signal is not affected significantly until a sunflower height of ca. $50 \mathrm{~cm}$. Temporal variability of $\Delta \theta_{\text {crop }}$ followed well temporal dynamics of crop height (Fig. 7 right side). Moreover, this temporal trend of $\Delta \theta_{\text {crop }}$ was also verified against estimations of leaf area index using Mailhol's model (1997) based on heat accumulation (Growing Degree Days).

The CRS signal is better understood with all environmental $\mathrm{H}$ pools considered, e.g. the study of Franz et al. (2013) at USA forest sites. In seasonal crops with fast-changing characteristics (i.e. aboveground biomass, biomass water content, root water content and others), these $\mathrm{H}$ pools may be not easily quantified due to limited frequency of measurements and invasiveness of existing measurement techniques (e.g. for roots and biomass). So alternatively, we proposed a simple measure to further understand the neutron attenuation by the presence of a crop.

Our simple approach was based on the calculation of the neutron counts by the inversion of the CRS equation for known FDR soil moisture, named $N_{\text {exp }}$. These are
HESSD

10, 4237-4274, 2013

Soil moisture measurement in cropped fields

C. A. Rivera Villarreyes et al.

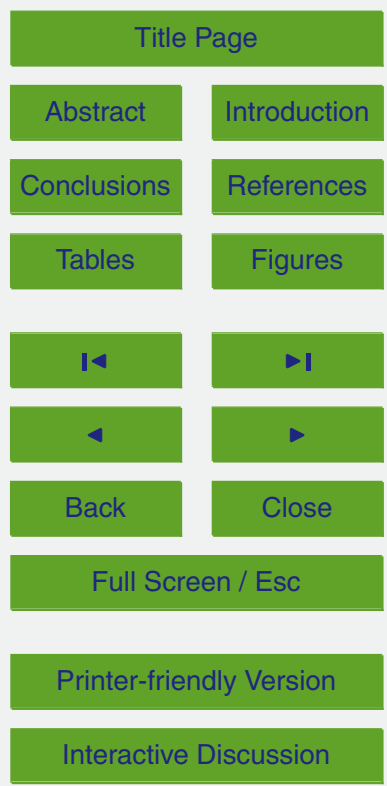


the neutrons counted if a crop would not have been present. The real number of counts $\left(N_{\mathrm{CRS}}\right)$ is directly measured in the CRS probe. Subsequently, the difference between $N_{\exp }$ and $N_{\text {CRS }}$ may be a measure of the attenuated neutrons by the crop presence $\left(N_{\text {att }}\right)$. Figure 8 shows the relation between $N_{\text {att }}$ and calibrated parameter $N_{0}$

5 for datasets D1-D6. Parameter $N_{0}$ was chosen as reference in order to compare neutrons versus neutrons. Results suggested an excellent agreement of $N_{0}$ with $N_{\text {att }}\left(r^{2}=\right.$ 0.973 ) for sunflower and winter rye. The decreased tendency of $N_{0}$ values with respect to $N_{\text {att }}$ (Fig. 8) was expected; the higher $N_{0}$ values at the initial sunflower stage corresponded to the lower values of $N_{\text {att }}$ and vice versa. Maximum attenuation occurred 10 at maximum crop stage in both sunflower and winter rye, i.e. large biomass and welldeveloped root structure. The fact that $N_{\text {att }}$ is not zero at the initial sunflower stage may be due to (i) its variability in biomass and root and/or (ii) Poisson's variability of neutron counts. Finally, we conclude that variability of $N_{0}$ substantially depends on the neutrons attenuated by additional $\mathrm{H}$ pools to soil moisture. Further research directions could be oriented to estimate values of $N_{\text {att }}$ from Monte Carlo neutron transport simulations with observed field profiles of soil moisture and situations with variable crop cover and root distribution. This information would provide an additional overview on how much $N_{\text {att }}$ is affected by a crop, as an entire system, and its parts in order to verify more precisely the link between $N_{0}$ and $N_{\text {att }}$.

\section{Summary and conclusions}

This study evaluates the applicability of the cosmic-ray neutron sensing method for soil moisture measurements in a farmland cropped with sunflower in 2011 and winter rye in 2012. The main objectives of this study were (i) to investigate different field calibration approaches for cropped fields, (ii) to observe the variation of calibration parameters

throughout the crop-growing season, and (iii) to extend knowledge of cosmic-ray neutron sensing to different crops. We presented three calibration approaches for the CRS probe (fully empirical, semi-empirical, and $N_{0}$-calibration) evaluated with six calibration

\section{HESSD}

$10,4237-4274,2013$

Soil moisture measurement in cropped fields

C. A. Rivera Villarreyes et al.

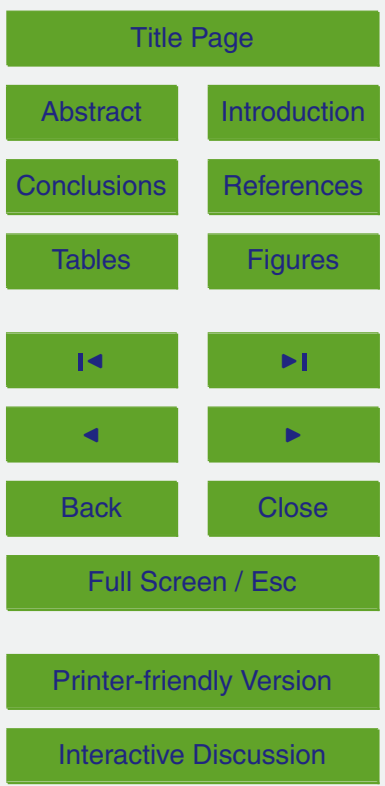


periods (sunflower and winter rye) and four calibration scenarios. This study kept the invariant known mathematical relation between fast neutrons and soil moisture. The CRS calibration parameters found in this study intend to suggest future research directions (e.g. crop correction factors) to make long-term CRS probe monitoring feasible, 5 especially in places with seasonal crops.

The CRS probe was calibrated against a FDR network, which observes soil moisture at the point scale and is used as ground truth. According to field information (soil texture, lattice water, soil moisture from two sampling campaigns and others), soil heterogeneity is not significant within the CRS measurement volume. Therefore, a much 10 denser FDR network would not modify the findings of this study. From calibration possibilities presented here, the fully empirical calibration approach provided the best calibration results compared to other two approaches, independent from the calibration scenarios. Calibration parameters are highly variable throughout the vegetative periods; therefore, improvement of CRS soil moisture mainly depends on the selection of 15 calibration period. Two calibration periods were identified to provide minimum values of RMSE, mid-season of sunflower (D3) and late season of winter rye (D6). Similarity in calibration results (D3 and D6) supports the consistency of the calibration approach and its independency from the FDR setup. It is worth mentioning that FDR sensor locations were not necessarily the same in both monitoring periods due to positioning accuracy, soil re-structure by farming practices, etc.

This study did not measure directly biomass components that may moderate fast neutrons (i.e. fresh matter and water content); instead crop height was used as a simple proxy to identify growing stages and, therefore, possible maximum periods of biomass. Likewise, other crop characteristics such as root density, cellulose fraction, stem diameter, etc., may be used at a degree similar to or higher than crop height.

From calibration scenarios designed in this study, the issues of the penetration depth and the soil moisture distribution in depth were also evaluated. Results did not reveal statistical differences using complex calibration scenarios with variable penetration

\section{HESSD}

$10,4237-4274,2013$

Soil moisture measurement in cropped fields

C. A. Rivera Villarreyes et al.

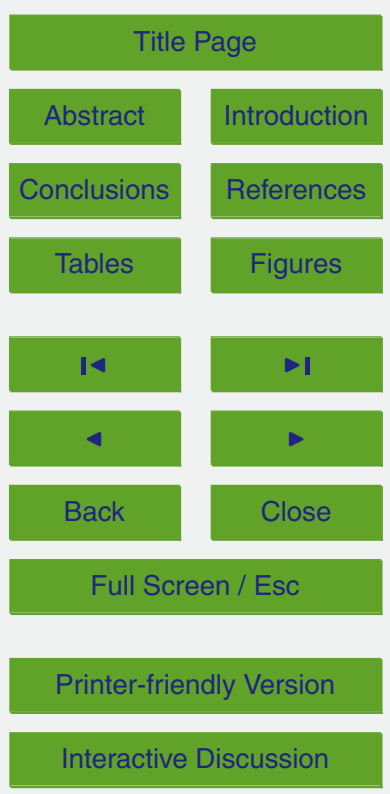


depth and weighting functions in depth. However, we expect these conclusions may change in other fields with strong vertical soil layering.

Overall, this study successfully tested the applicability of the cosmic-ray neutron sensing methodology in cropped fields. The message and conclusions to take home 5 from this study are condensed into the following four points: (i) the CRS-derived soil moisture for cropped fields is highly affected throughout the growing periods, and (ii) its calibration parameters are time-dependent and crop-dependent. Parameter variability between sunflower and winter rye may be attributed to how these crops modify its crop water content (temporal and spatial) and other characteristics throughout its growing 10 period. Moreover, (iii) CRS uncertainty can be related to some properties such as crop height, and the CRS parameter variability $\left(N_{0}\right)$ could be associated by predicting the attenuated neutrons by crop presence. In general, (iv) the cosmic-ray neutron sensing methodology has the potential to provide measurements between point scale and remote sensing scale; however, special attention should be taken in cropped fields.

15 A further recommendation of this study is the need for neutron correction factors to deal with the problem of the biomass influence (and other crop characteristics) on the CRS soil moisture.

Acknowledgement. This study was partly funded by the German Ministry of Education and Research (BMBF) as part of IPSWaT (International Postgraduate Studies in Water Technolo20 gies). The research was supported by the Helmholtz Centre for Environmental Research (UFZ) and TERENO (Terrestrial Environmental Observatories) by providing the cosmic-ray sensor. Furthermore, we thank the Leibniz Institute for Agricultural Engineering Potsdam-Bornim (ATB) for their support, especially Robin Gebbers for conveying the experimental site and supporting our field work in Bornim. We also acknowledge the NMDB database (www.nmdb.eu), founded 25 under the European Union's FP7 programme (contract no. 213007) for providing cosmic-ray data, namely from the Jungfraujoch, JUNG, station. We also thank Ute Wollschläger (UFZ) and Steffen Zacharias (UFZ) for their critical and helpful comments in a previous version of this manuscript.

HESSD

10, 4237-4274, 2013

Soil moisture measurement in cropped fields

C. A. Rivera Villarreyes et al.

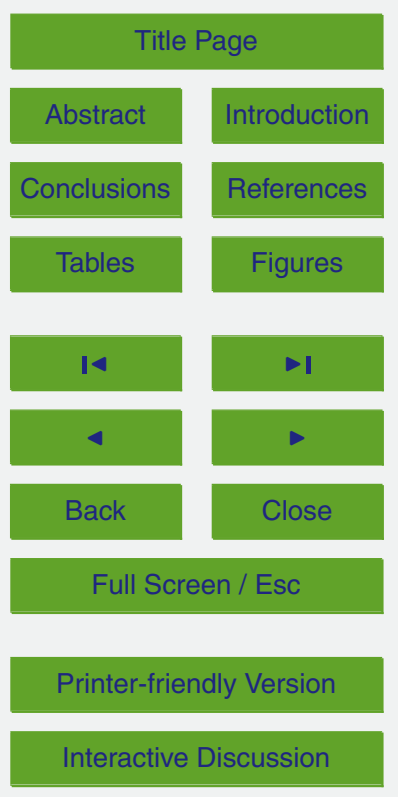




\section{References}

Albergel, C., Calvet, J.-C., de Rosnay, P., Balsamo, G., Wagner, W., Hasenauer, S., Naeimi, V., Martin, E., Bazile, E., Bouyssel, F., and Mahfouf, J.-F.: Cross-evaluation of modelled and remotely sensed surface soil moisture with in situ data in southwestern France, Hydrol. Earth Syst. Sci., 14, 2177-2191, doi:10.5194/hess-14-2177-2010, 2010.

Albergel, C., de Rosnay, P., Gruhier, C., Muñoz-Sabater, J., Hasenauer, S., Isaksen, L., Kerr, Y., and Wagner, W.: Evaluation of remotely sensed and modelled soil moisture products using global ground-based in situ observations, Remote Sens. Environ., 118, 215-226, 2012.

Bogena, H. R., Herbst, M., Huisman, J. A., Rosenbaum, U., Weuthen, A., and Vereecken, H.: Potential of wireless sensor networks for measuring soil water content variability, Vadose Zone J., 9, 1002-1013, doi:10.2136/vzj2009.0173, 2010.

Brocca, L., Melone, F., Moramarco, T., Wagner, W., Naeimi, V., Bartalis, Z., and Hasenauer, S.: Improving runoff prediction through the assimilation of the ASCAT soil moisture product, Hydrol. Earth Syst. Sci., 14, 1881-1893, doi:10.5194/hess-14-1881-2010, 2010.

15 Champagne, C., McNairn, H., and Berg, A. A.: Monitoring agricultural soil moisture extremes in Canada using passive microwave remote sensing, Remote Sens. Environ., 115, 2434-2444, 2011.

Choi, M. and Jacobs, J. M.: Soil moisture variability of root zone profiles within SMEX02 remote sensing footprints, Adv. Water Resour., 30, 883-896, doi:10.1016/j.advwatres.2006.07.007, 2007.

Christiansen, L., Haarder, E. B., Hansen, A. B., Looms, M. C., Binning, P. J., Rosbjerg, D., Andersen, O. B., and Bauer-Gottwein, P.: Calibrating Vadose Zone Models with time-lapse gravity data, Vadose Zone J., 10, 1034-1044, doi:10.2136/vzj2010.0127, 2011.

Desilets, D., Zreda, M., and Ferré, T. P. A.: Nature's neutron probe: Land surface hydrology at an elusive scale with cosmic rays, Water Resour. Res., 46, W11505, doi:10.1029/2009wr008726, 2010.

Dorigo, W. A., Wagner, W., Hohensinn, R., Hahn, S., Paulik, C., Xaver, A., Gruber, A., Drusch, M., Mecklenburg, S., van Oevelen, P., Robock, A., and Jackson, T.: The International Soil Moisture Network: a data hosting facility for global in situ soil moisture measurements,

30 Hydrol. Earth Syst. Sci., 15, 1675-1698, doi:10.5194/hess-15-1675-2011, 2011.

Driscoll, W. C.: Robustness of the ANOVA and Tukey-Kramer statistical tests, Comput. Ind. Eng., 31, 265-268, 1996.
HESSD

10, 4237-4274, 2013

Soil moisture

measurement in

cropped fields

C. A. Rivera Villarreyes

et al.

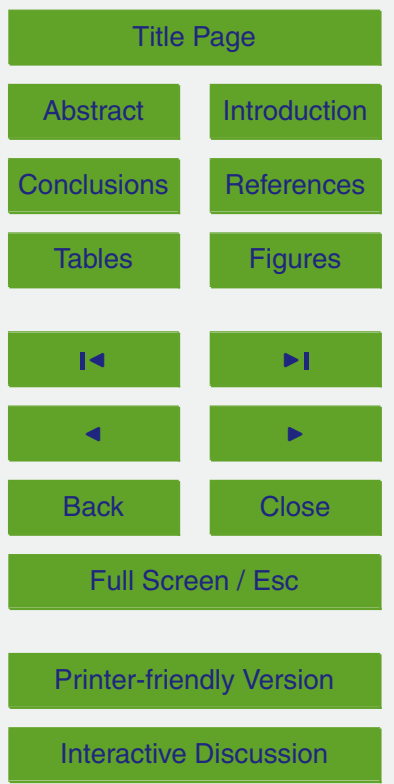


Entekhabi, D., Njoku, E. G., O’Neill, P. E., Kellogg, K. H., Crow, W. T., Edelstein, W. N., Entin, J. K., Goodman, S. D., Jackson, T. J., Johnson, J., Kimball, J., Piepmeier, J. R., Koster, R. D., Martin, N., McDonald, K. C., Moghaddam, M., Moran, S., Reichle, R., Shi, J. C., Spencer, M. W., Thurman, S. W., Tsang, L., and Van Zyl, J.: The Soil Moisture Active Passive (SMAP) Mission, P. IEEE, 98, 704-716, doi:10.1109/JPROC.2010.2043918, 2010.

Franz, T. E., Zreda, M., Ferre, T. P. A., Rosolem, R., Zweck, C., Stillman, S. Z. X., and Shuttleworth, W. J.: Measurement depth of the cosmic-ray soil moisture probe affected by hydrogen from various sources, Water Resour. Res., 48, W08515, doi:10.1029/2012wr011871, 2012a.

Franz, T. E., Zreda, M., Rosolem, R., and Ferre, T. P. A.: Field Validation of a cosmic-ray neutron sensor using a distributed sensor network, Vadose Zone J., 11, 4, doi:10.2136/vzj2012.0046, 2012b.

Franz, T. E., Zreda, M., Rosolem, R., and Ferre, T. P. A.: A universal calibration function for determination of soil moisture with cosmic-ray neutrons, Hydrol. Earth Syst. Sci., 17, 453460, doi:10.5194/hess-17-453-2013, 2013.

Garre, S., Javaux, M., Vanderborght, J., Pages, L., and Vereecken, H.: Three-dimensional electrical resistivity tomography to monitor root zone water dynamics, Vadose Zone J., 10, 412424, doi:10.2136/vzj2010.0079, 2011.

Graeff, T., Zehe, E., Schlaeger, S., Morgner, M., Bauer, A., Becker, R., Creutzfeldt, B., and Bronstert, A.: A quality assessment of Spatial TDR soil moisture measurements in homogenous and heterogeneous media with laboratory experiments, Hydrol. Earth Syst. Sci., 14, 1007-1020, doi:10.5194/hess-14-1007-2010, 2010.

Hassanein, R., Lehmann, E., and Vontobel, P.: Methods of scattering corrections for quantitative neutron radiography, Nucl. Instrum. Meth. A, 542, 353-360, 2005.

Hess, W. N., Canfield, E. H., and Lingenfelter, R. E.: Cosmic-ray neutron demography, J. Geophys. Res., 66, 665-677, doi:10.1029/JZ066i003p00665, 1961.

Hornbuckle, B., Irvin, S., Franz, T. E., Rosolem, R., and Zweck, C.: The potential of the COSMOS network to be a source of new soil moisture information for SMOS and SMAP, in: Proc. Geoscience and Remote Sensing Symposium (IGARSS), 22-27 July 2012, Munich, Germany, IEEE International, 1243-1246, doi:10.1109/IGARSS.2012.6351317, 2012.

so Huisman, J. A., Hubbard, S. S., Redman, J. D., and Annan, A. P.: Measuring soil water content with ground penetrating radar: a review, Vadose Zone J., 2, 476-491, doi:10.2136/vzj2003.4760, 2003.
HESSD

10, 4237-4274, 2013

Soil moisture

measurement in

cropped fields

C. A. Rivera Villarreyes

et al.

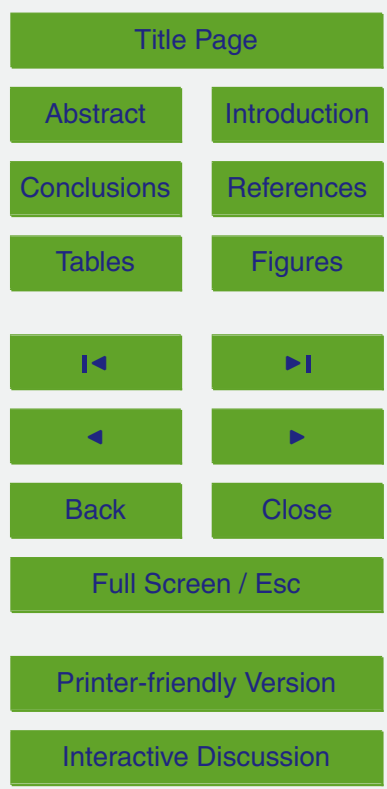


Hydroinnova: Technical Document 01-07: Soil Water Content Measurements with Cosmic Rays, Albuquerque, New Mexico, 2010.

Kodama, M.: Continuous monitoring of snow water equivalent using cosmic ray neutrons, Cold Reg. Sci. Technol., 3, 295-303, 1980.

5 Kodama, M.: An introduction to applied cosmic ray physics, Jpn. J. Appl. Phys., 23, 726-728, 1984.

Kodama, M., Kudo, S., and Kosuge, T.: Application of atmospheric neutrons to soil moisture measurement, Soil Sci., 140, 237-242, 1985.

Koster, R. D., Mahanama, S. P. P., Livneh, B., Lettenmaier, D. P., and Reichle, R. H.: Skill in streamflow forecasts derived from large-scale estimates of soil moisture and snow, Nat. Geosci., 3, 613-616, 2010.

Mailhol, J. C., Olufayo, A. A., and Ruelle, P.: Sorghum and sunflower evapotranspiration and yield from simulated leaf area index, Agr. Water Manage., 35, 167-182, 1997.

Neutron Monitor Database: available at: http://www.nmdb.eu/, last access: 5 March, 2013.

15 Oswald, S. E., Menon, M., Carminati, A., Vontobel, P., Lehmann, E., and Schulin, R.: Quantitative imaging of infiltration, root growth, and root water uptake via neutron radiography, Vadose Zone J., 7, 1035-1047, doi:10.2136/vzj2007.0156, 2008.

Patterson, B. M. and Bekele, E. B.: A novel technique for estimating wetting front migration rates through the vadose zone based on changes in groundwater velocity, J. Hydrol., 409, $20 \quad 538-544,2011$.

Porporato, A. and Rodriguez-Iturbe, I.: Ecohydrology-a challenging multidisciplinary research perspective/ ecohydrologie: une perspective stimulante de recherche multidisciplinaire, Hydrolog. Sci. J., 47, 811-821, doi:10.1080/02626660209492985, 2002.

Rivera Villarreyes, C. A., Baroni, G., and Oswald, S. E.: Integral quantification of seasonal soil moisture changes in farmland by cosmic-ray neutrons, Hydrol. Earth Syst. Sci., 15, 38433859, doi:10.5194/hess-15-3843-2011, 2011.

Robinson, D. A., Campbell, C. S., Hopmans, J. W., Hombuckle, B. K., Jones, S. B., Knight, R., Ogden, F., Selker, J., and Wendroth, O.: Soil moisture measurement for ecological and hydrological watershed-scale observatories: a review, Vadose Zone J., 7, 358-389, doi:10.2136/vzj2007.0143, 2008.

Schwank, M., Wiesmann, A., Werner, C., Mätzler, C., Weber, D., Murk, A., Völksch, I., and Wegmüller, U.: ELBARA II, an L-band radiometer system for soil moisture research, Sensors, 10, 584-612, 2009.

HESSD

10, 4237-4274, 2013

Soil moisture

measurement in

cropped fields

C. A. Rivera Villarreyes

et al.

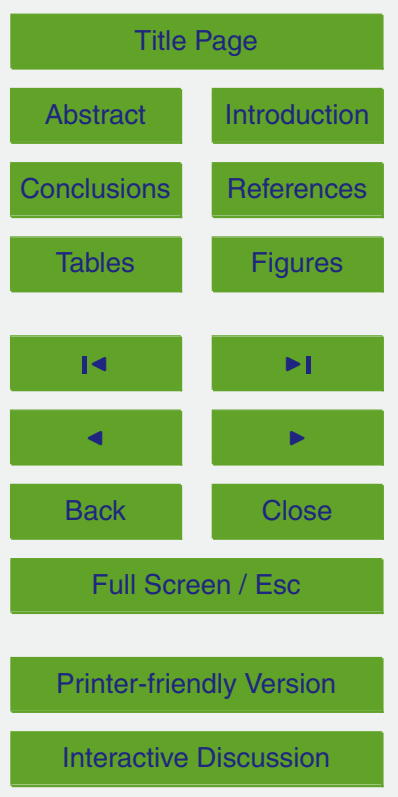


Silvapulle, M. J.: On an F-type statistic for testing one-sided hypotheses and computation of chi-bar-squared weights, Stat. Probabil. Lett., 28, 137-141, 1996.

Steenbergen, N. V. and Willems, P.: Method for testing the accuracy of rainfall-runoff models in predicting peak flow changes due to rainfall changes, in a climate changing context, J.

5 Hydrol., 414-415, 425-434, 2012.

Sun, H., Nelson, M., Chen, F., and Husch, J.: Soil mineral structural water loss during LOI analyses, Can. J. Soil Sci., 89, 603-610, 2009.

Tapley, B. D., Bettadpur, S., Ries, J. C., Thompson, P. F., and Watkins, M. M.: GRACE measurements of mass variability in the earth system, Science, 305, 503-505, doi:10.1126/science.1099192, 2004.

Team, T. G., Koster, R. D., Dirmeyer, P. A., Guo, Z., Bonan, G., Chan, E., Cox, P., Gordon, C. T., Kanae, S., Kowalczyk, E., Lawrence, D., Liu, P., Lu, C. H., Malyshev, S., McAvaney, B., Mitchell, K., Mocko, D., Oki, T., Oleson, K., Pitman, A., Sud, Y. C., Taylor, C. M., Verseghy, D., Vasic, R., Xue, Y., and Yamada, T.: Regions of strong coupling between soil moisture and precipitation, Science, 305, 1138-1140, doi:10.1126/science.1100217, 2004.

Vereecken, H., Huisman, J. A., Bogena, H. R., Vanderborght, J., Vrugt, J. A., and Hopmans, J. W.: On the value of soil moisture measurements in vadose zone hydrology: a review., Water Resour. Res., 44, W00D06, doi:10.1029/2008WR006829, 2008.

Vico, G. and Porporato, A.: From rainfed agriculture to stress-avoidance irrigation: I. A generalized irrigation scheme with stochastic soil moisture, Adv. Water Resour., 34, 263-271, 2011.

Western, A. W., Grayson, R. B., and Blöshl, G.: Scaling of soil moisture: a hydrologic perspective, Annu. Rev. Earth PI. Sc., 30, 149-180, doi:10.1146/annurev.earth.30.091201.140434, 2002.

Zreda, M., Desilets, D., Ferré, T. P. A., and Scott, R. L.: Measuring soil moisture content noninvasively at intermediate spatial scale using cosmic-ray neutrons, Geophys. Res. Lett., 35, $1-5,2008$.

Zreda, M., Shuttleworth, W. J., Zeng, X., Zweck, C., Desilets, D., Franz, T., and Rosolem, R.: COSMOS: the COsmic-ray Soil Moisture Observing System, Hydrol. Earth Syst. Sci., 16, 4079-4099, doi:10.5194/hess-16-4079-2012, 2012.

\section{HESSD}

10, 4237-4274, 2013

Soil moisture

measurement in

cropped fields

C. A. Rivera Villarreyes

et al.

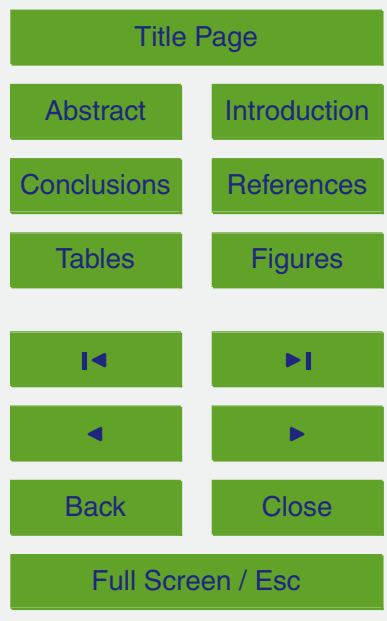

Printer-friendly Version

Interactive Discussion 


\section{HESSD}

10, 4237-4274, 2013

Soil moisture

measurement in

cropped fields

Table 1. Definition of calibration approaches applied in this study for the sunflower period. The $\theta_{\mathrm{CRS}}$ is the volumetric areal mean soil moisture $\left[\mathrm{m}^{3} \mathrm{~m}^{-3}\right], N$ is the corrected neutron counting rate $[-], \rho_{\mathrm{b}}$ is the mean bulk density $\left[\mathrm{kg} \mathrm{m}^{-3}\right], \rho_{\mathrm{w}}$ is water density $\left[\mathrm{kg} \mathrm{m}^{-3}\right], a_{i}$ are dimensionless calibration parameters [-], and $N_{0}$ is defined as the corrected neutron counting rate over dry soil under the same reference conditions used for $N$. Note that the $N_{0}$ value for the fully empirical and semi-empirical approaches was set up to the maximum counting rate measured in the field.

\begin{tabular}{ccc}
\hline Calibration approach & Equation & Fitting parameters \\
\hline Fully empirical & $\theta_{\mathrm{CRS}}=\frac{a_{o}}{N / N_{0}-a_{1}}-a_{2}$ & $a_{0}, a_{1}, a_{2}$ \\
Semi-empirical & $\theta_{\mathrm{CRS}}=\left(\frac{0.0808}{N / N_{0}-0.372}-0.115\right) \cdot f_{\text {cal }}$ & $f_{\text {cal }}$ \\
$N_{0}$-calibration & $\theta_{\mathrm{CRS}}=\frac{0.0808}{N / N_{0}-0.372}-0.115$ & $N_{0}$ \\
\hline
\end{tabular}

C. A. Rivera Villarreyes

et al.

Title Page 
Table 2. Field characteristics of the calibration periods during sunflower and winter rye periods. Notice that FDR soil moisture presented in the table corresponds to the mean value at 5,20 and $40 \mathrm{~cm}$ depth.

\begin{tabular}{lllcrr}
\hline Period & Crop & $\begin{array}{l}\text { Growing } \\
\text { stage }\end{array}$ & $\begin{array}{r}\text { Duration } \\
{[\text { days }]}\end{array}$ & $\begin{array}{r}\text { Crop height } \\
{[\mathrm{cm}]}\end{array}$ & $\begin{array}{r}\text { FDR soil moisture } \\
{\left[\mathrm{m}^{3} \mathrm{~m}^{-3}\right]}\end{array}$ \\
\hline D1 & Sunflower & Initial & 30 & $5-30$ & $0.069-0.119$ \\
D2 & Sunflower & Development & 30 & $30-110$ & $0.046-0.141$ \\
D3 & Sunflower & Mid-season & 30 & $110-150$ & $0.090-0.224$ \\
D4 & Sunflower & Late & 34 & $110-125$ & $0.122-0.165$ \\
D5 & Winter rye & Mid-season & 40 & $30-140$ & $0.045-0.105$ \\
D6 & Winter rye & Late & 33 & $140-150$ & $0.057-0.179$ \\
\hline
\end{tabular}

HESSD

10, 4237-4274, 2013

Soil moisture measurement in

cropped fields

C. A. Rivera Villarreyes

et al.

\section{Title Page}

Abstract Introduction

Conclusions

References

Tables

Figures

14

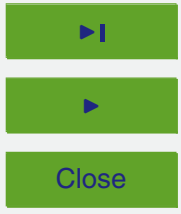

Back

\section{Full Screen / Esc}

Printer-friendly Version

Interactive Discussion 
Table A1. Fully empirical calibration approach and its four calibration scenarios: (S1) constant $z^{*}$ and no neutron weighting scheme, (S2) variable $z^{*}$ and no neutron weighting scheme, (S3) constant $z^{*}$ and neutron weighting scheme, and (S4) variable $z^{*}$ and neutron weighting scheme. The RMSE was calculated for the entire monitoring period.

\begin{tabular}{cccccccc}
\hline Scenarios & Datasets & Crop & $\begin{array}{c}a_{0} \\
{[-]}\end{array}$ & $\begin{array}{c}a_{1} \\
{[-]}\end{array}$ & $\begin{array}{c}a_{2} \\
{[-]}\end{array}$ & $\begin{array}{c}k \\
{[-]}\end{array}$ & $\begin{array}{c}\mathrm{RMSE} \\
{\left[\mathrm{m}^{3} \mathrm{~m}^{-3}\right]}\end{array}$ \\
\hline S1 & D1 & Sunflower & 0.133 & 0.001 & 0.076 & & 0.025 \\
S1 & D2 & Sunflower & 0.035 & 0.219 & 0.001 & & 0.036 \\
S1 & D3 & Sunflower & 0.050 & 0.319 & 0.039 & & 0.019 \\
S1 & D4 & Sunflower & 0.092 & 0.001 & 0.001 & & 0.040 \\
S2 & D1 & Sunflower & 0.137 & 0.001 & 0.087 & & 0.022 \\
S2 & D2 & Sunflower & 0.035 & 0.283 & 0.001 & & 0.027 \\
S2 & D3 & Sunflower & 0.055 & 0.303 & 0.043 & & 0.019 \\
S2 & D4 & Sunflower & 0.086 & 0.001 & 0.001 & & 0.034 \\
S3 & D1 & Sunflower & 0.124 & 0.001 & 0.062 & -0.010 & 0.026 \\
S3 & D2 & Sunflower & 0.037 & 0.219 & 0.001 & -0.010 & 0.033 \\
S3 & D3 & Sunflower & 0.063 & 0.284 & 0.057 & -2.965 & 0.019 \\
S3 & D4 & Sunflower & 0.094 & 0.001 & 0.001 & -0.010 & 0.042 \\
S4 & D1 & Sunflower & 0.124 & 0.001 & 0.062 & -0.010 & 0.026 \\
S4 & D2 & Sunflower & 0.037 & 0.219 & 0.001 & -0.010 & 0.033 \\
S4 & D3 & Sunflower & 0.059 & 0.295 & 0.050 & -1.887 & 0.019 \\
S4 & D4 & Sunflower & 0.093 & 0.001 & 0.001 & -0.050 & 0.041 \\
S1 & D5 & Winter rye & 0.113 & 0.001 & 0.070 & & 0.023 \\
S1 & D6 & Winter rye & 0.038 & 0.374 & 0.024 & & 0.019 \\
S2 & D5 & Winter rye & 0.071 & 0.188 & 0.049 & & 0.022 \\
S2 & D6 & Winter rye & 0.038 & 0.374 & 0.024 & & 0.019 \\
S3 & D5 & Winter rye & 0.138 & 0.001 & 0.105 & -1.021 & 0.021 \\
S3 & D6 & Winter rye & 0.069 & 0.282 & 0.066 & -2.015 & 0.019 \\
S4 & D5 & Winter rye & 0.135 & 0.001 & 0.101 & -0.890 & 0.021 \\
S4 & D6 & Winter rye & 0.056 & 0.323 & 0.050 & -1.522 & 0.019 \\
\hline
\end{tabular}

HESSD

$10,4237-4274,2013$

Soil moisture

measurement in

cropped fields

C. A. Rivera Villarreyes et al.

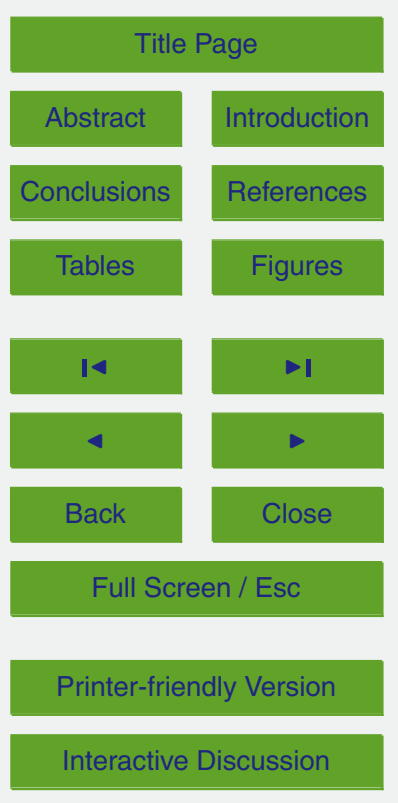


Table A2. Semi-empirical calibration approach and its four calibration scenarios: (S1) constant $z^{*}$ and no neutron weighting scheme, (S2) variable $z^{*}$ and no neutron weighting scheme, (S3) constant $z^{*}$ and neutron weighting scheme, and (S4) variable $z^{*}$ and neutron weighting scheme. The RMSE was calculated for the entire monitoring period.

\begin{tabular}{cccccc}
\hline Scenario & Dataset & Crop & $\begin{array}{c}f_{\text {cal }} \\
{[-]}\end{array}$ & $\begin{array}{c}k \\
{[-]}\end{array}$ & $\begin{array}{c}\text { RMSE } \\
{\left[\mathrm{m}^{3} \mathrm{~m}^{-3}\right]}\end{array}$ \\
\hline S1 & D1 & Sunflower & 1.002 & & 0.058 \\
S1 & D2 & Sunflower & 0.529 & & 0.032 \\
S1 & D3 & Sunflower & 0.583 & & 0.028 \\
S1 & D4 & Sunflower & 0.670 & & 0.026 \\
S2 & D1 & Sunflower & 0.936 & & 0.049 \\
S2 & D2 & Sunflower & 0.605 & & 0.027 \\
S2 & D3 & Sunflower & 0.587 & & 0.028 \\
S2 & D4 & Sunflower & 0.627 & & 0.026 \\
S3 & D1 & Sunflower & 0.963 & -1.001 & 0.053 \\
S3 & D2 & Sunflower & 0.550 & -3.129 & 0.030 \\
S3 & D3 & Sunflower & 0.590 & -2.404 & 0.028 \\
S3 & D4 & Sunflower & 0.608 & $<-10$ & 0.027 \\
S4 & D1 & Sunflower & 0.912 & -1.961 & 0.046 \\
S4 & D2 & Sunflower & 0.554 & -2.737 & 0.030 \\
S4 & D3 & Sunflower & 0.588 & -1.559 & 0.028 \\
S4 & D4 & Sunflower & 0.607 & $<-10$ & 0.027 \\
S1 & D5 & Winter rye & 0.796 & & 0.033 \\
S1 & D6 & Winter rye & 0.699 & & 0.026 \\
S2 & D5 & Winter rye & 0.773 & & 0.031 \\
S2 & D6 & Winter rye & 0.699 & & 0.026 \\
S3 & D5 & Winter rye & 0.789 & -2.600 & 0.032 \\
S3 & D6 & Winter rye & 0.728 & -1.499 & 0.028 \\
S4 & D5 & Winter rye & 0.792 & -2.340 & 0.033 \\
S4 & D6 & Winter rye & 0.729 & -1.340 & 0.028 \\
\hline
\end{tabular}

HESSD

10, 4237-4274, 2013

Soil moisture

measurement in

cropped fields

C. A. Rivera Villarreyes et al.

Title Page

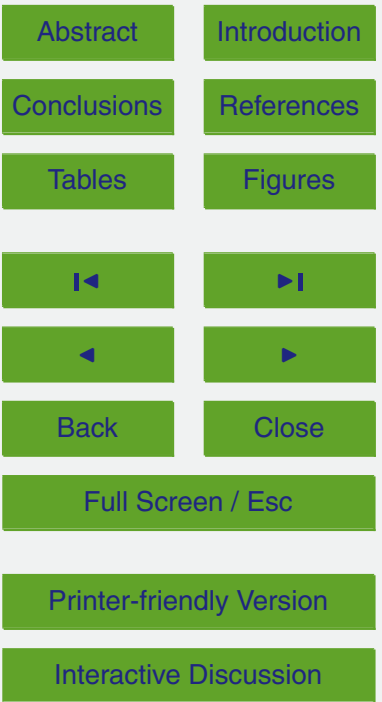


Table A3. $N_{0}$-calibration approach and its four calibration scenarios: (S1) constant $z^{*}$ and no neutron weighting scheme, (S2) variable $z^{*}$ and no neutron weighting scheme, (S3) constant $z^{*}$ and neutron weighting scheme, and (S4) variable $z^{*}$ and neutron weighting scheme. The RMSE was calculated for the entire monitoring period.

\begin{tabular}{cccccc}
\hline Scenario & Dataset & Crop & $\begin{array}{c}N_{0} \\
{[\mathrm{cph}]}\end{array}$ & $\begin{array}{c}k \\
{[-]}\end{array}$ & $\begin{array}{c}\mathrm{RMSE} \\
{\left[\mathrm{m}^{3} \mathrm{~m}^{-3}\right]}\end{array}$ \\
\hline S1 & D1 & Sunflower & 1333.0 & & 0.059 \\
S1 & D2 & Sunflower & 1159.4 & & 0.033 \\
S1 & D3 & Sunflower & 1162.7 & & 0.033 \\
S1 & D4 & Sunflower & 1202.4 & & 0.029 \\
S2 & D1 & Sunflower & 1312.1 & & 0.051 \\
S2 & D2 & Sunflower & 1191.2 & & 0.029 \\
S2 & D3 & Sunflower & 1164.6 & & 0.033 \\
S2 & D4 & Sunflower & 1182.9 & & 0.030 \\
S3 & D1 & Sunflower & 1331.8 & -0.195 & 0.058 \\
S3 & D2 & Sunflower & 1169.7 & -5.291 & 0.032 \\
S3 & D3 & Sunflower & 1166.1 & -2.475 & 0.032 \\
S3 & D4 & Sunflower & 1173.4 & $<-10$ & 0.031 \\
S4 & D1 & Sunflower & 1320.4 & -0.807 & 0.054 \\
S4 & D2 & Sunflower & 1171.1 & -4.968 & 0.031 \\
S4 & D3 & Sunflower & 1165.2 & -1.607 & 0.032 \\
S4 & D4 & Sunflower & 1173.0 & $<-10$ & 0.031 \\
S1 & D5 & Winter rye & 1274.5 & & 0.038 \\
S1 & D6 & Winter rye & 1229.9 & & 0.030 \\
S2 & D5 & Winter rye & 1266.0 & & 0.036 \\
S2 & D6 & Winter rye & 1229.9 & & 0.030 \\
S3 & D5 & Winter rye & 1268.9 & -3.064 & 0.037 \\
S3 & D6 & Winter rye & 1242.6 & -1.749 & 0.031 \\
S4 & D5 & Winter rye & 1270.0 & -2.790 & 0.037 \\
S4 & D6 & Winter rye & 1243.1 & -1.574 & 0.031 \\
\hline & & & & & \\
\hline
\end{tabular}

HESSD

10, 4237-4274, 2013

Soil moisture

measurement in

cropped fields

C. A. Rivera Villarreyes et al.

\section{Title Page}

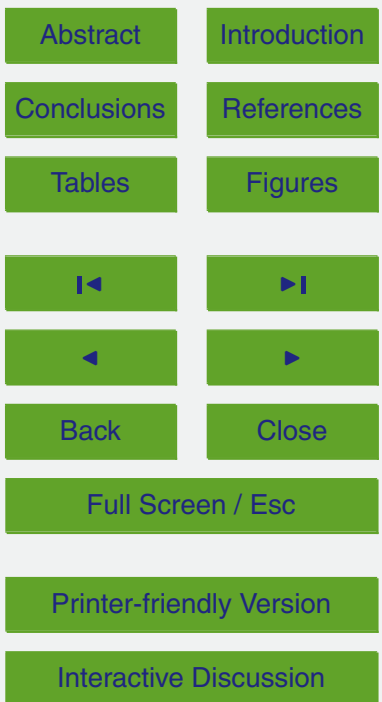




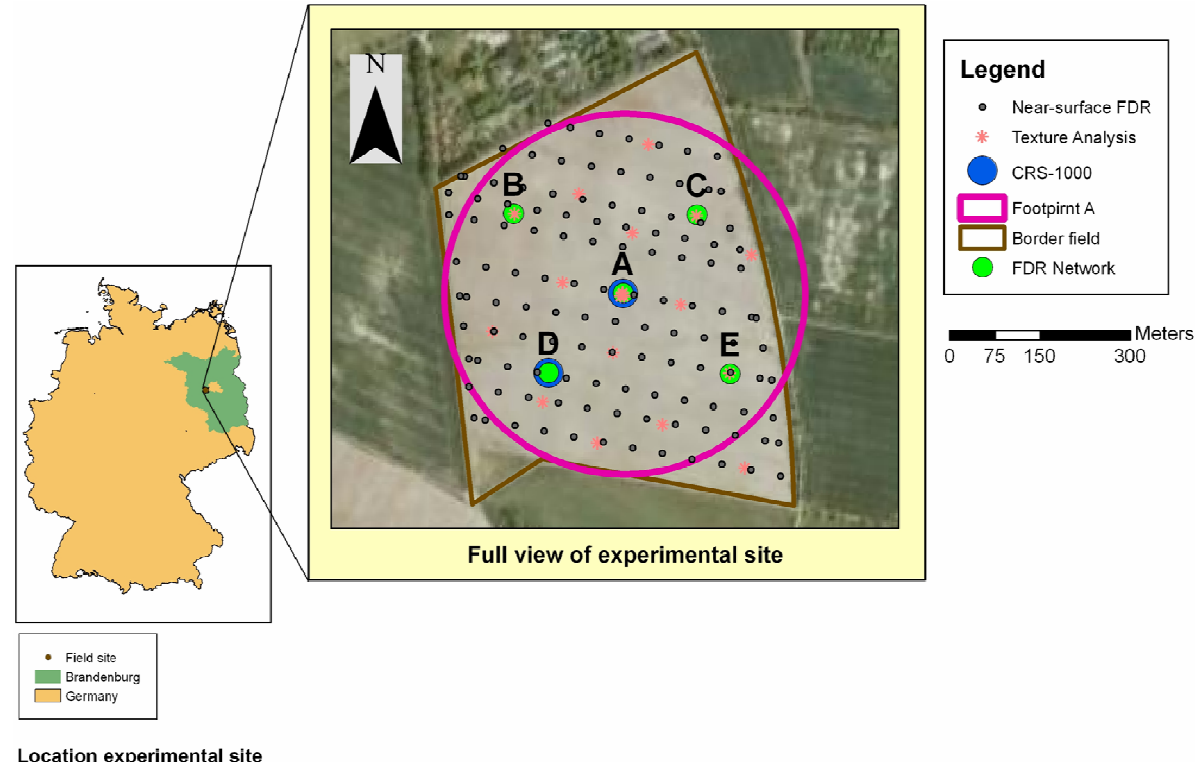

Fig. 1. Monitoring network in Bornim during sunflower and winter rye periods: FDR soil moisture network $(A-E)$ and CRS probe at location A. Theoretical CRS probe footprint is represented by a 600 m-diameter circle.

\section{HESSD}

10, 4237-4274, 2013

\section{Soil moisture} measurement in cropped fields

C. A. Rivera Villarreyes et al.

\section{Title Page}

\section{Abstract}

Conclusions

Tables

14

$\triangleleft$

Back
Introduction

References

Figures

$\rightarrow$

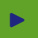

Close

\section{Full Screen / Esc}

Printer-friendly Version

Interactive Discussion 


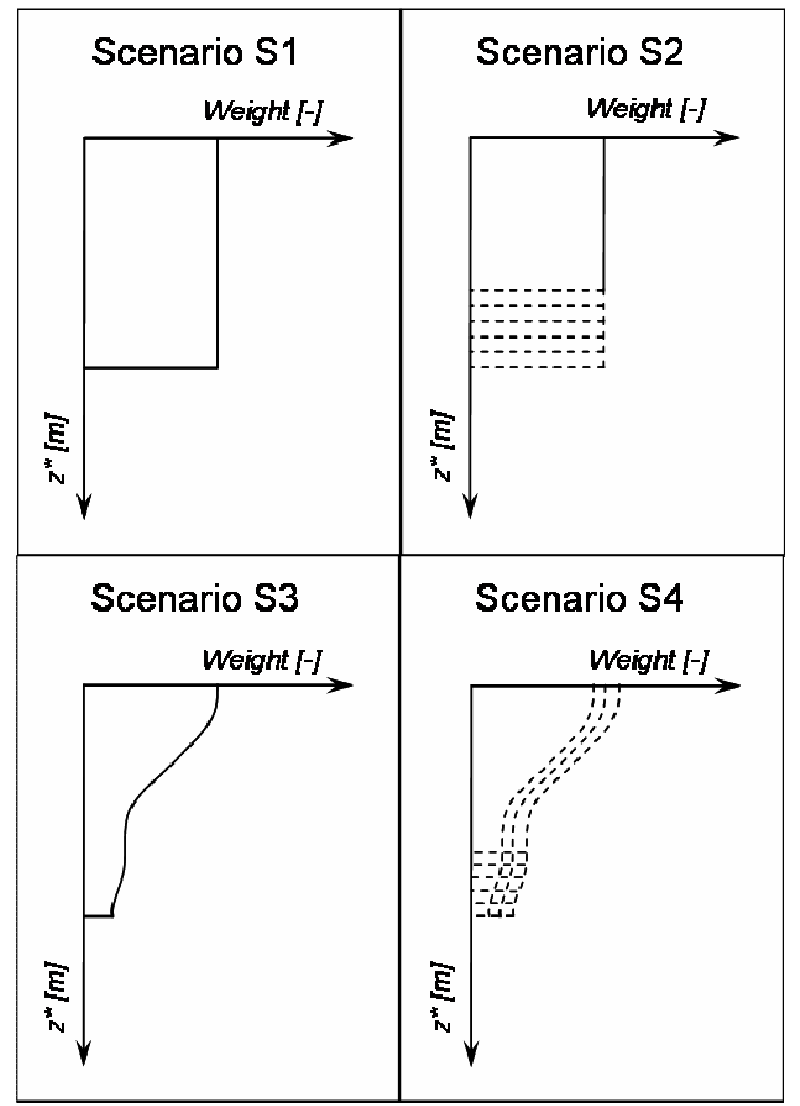

HESSD

10, 4237-4274, 2013

Soil moisture measurement in

cropped fields

C. A. Rivera Villarreyes

et al.

Title Page

Abstract Introduction

Conclusions References

Tables

Figures

14

$\rightarrow$

$\triangleleft$

Back

Close

Full Screen / Esc

Fig. 2. Scheme of calibration approaches: constant penetration depth and constant neutron weights in depth (S1), time-variable penetration depth and constant neutron weights in depth (S2), constant penetration depth and space-variable neutron weights in depth (S3), and timevariable penetration depth and space-variable neutron weights in depth (S4). 


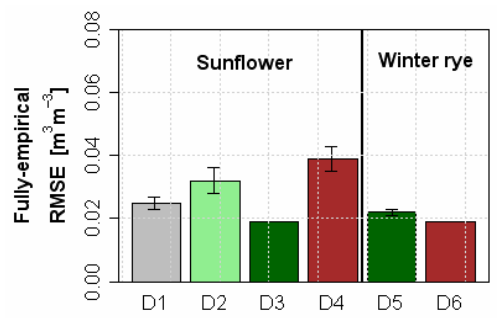

HESSD

10, 4237-4274, 2013

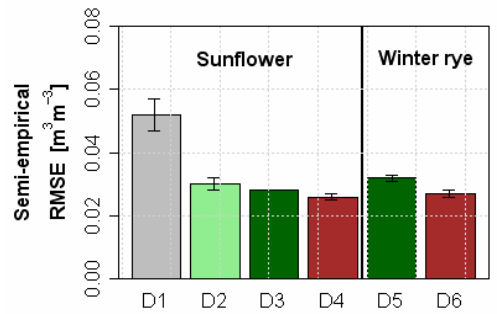

\section{Soil moisture measurement in \\ cropped fields}

C. A. Rivera Villarreyes

et al.

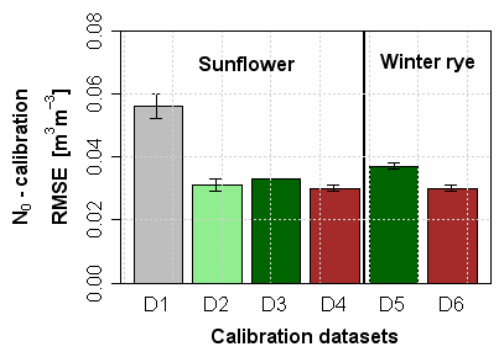

Fig. 3. Comparison of the three calibration approaches in terms of root mean square error (RMSE, $\left[\mathrm{m}^{3} \mathrm{~m}^{-3}\right]$ ) for the fully empirical approach (upper graph), semi-empirical approach (middle graph), and $\mathrm{N}_{0}$-calibration approach (lower graph) applied for six calibration datasets (Table 2) and four calibration scenarios (Fig. 2). Notice that (i) the error bars are defined by one standard deviation computed from the calibration scenarios and (ii) RMSE is calculated for the two monitoring periods. Different bar colors indicate different crop stages.

Title Page

Abstract Introduction

Conclusions References

Tables Figures

14 $\rightarrow 1$

4

Back

Close

\section{Full Screen / Esc}

Printer-friendly Version

Interactive Discussion 


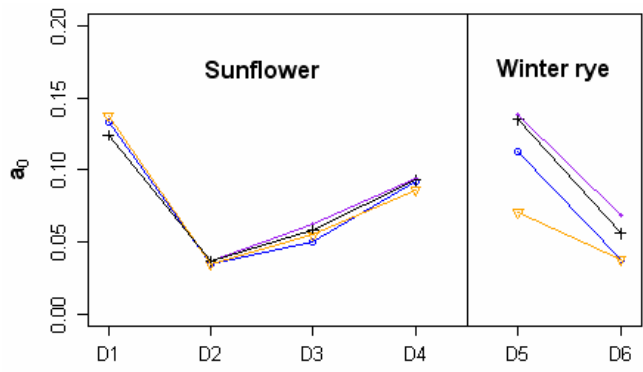

\section{Soil moisture measurement in cropped fields}

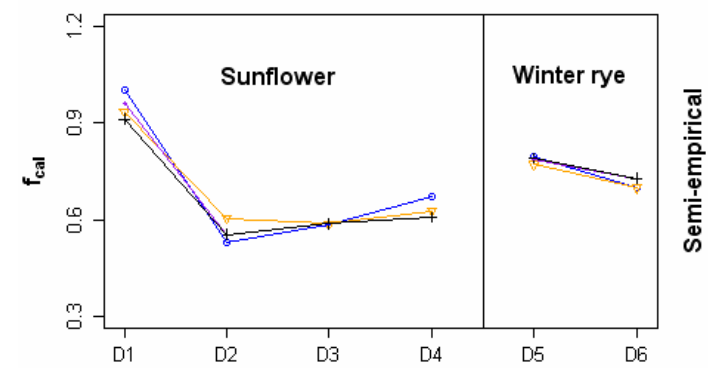

C. A. Rivera Villarreyes et al.

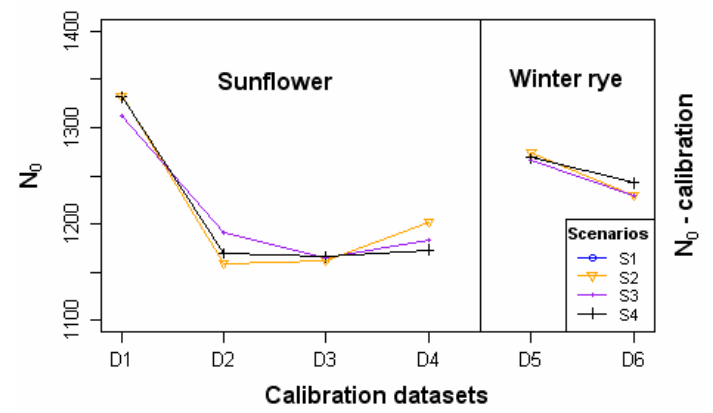

Title Page

Abstract Introduction

Conclusions

References

Tables

Figures

14

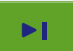

4

Back

Close

Full Screen / Esc

Printer-friendly Version

Fig. 4. Variation of calibration parameters throughout the growing periods for sunflower (left) and winter rye (right) for different calibration scenarios (Fig. 2). The values of $a_{0}, f_{\text {cal }}$ and $N_{0}$ are related to the fully empirical, semi-empirical and $N_{0}$-calibration approaches.

Interactive Discussion 

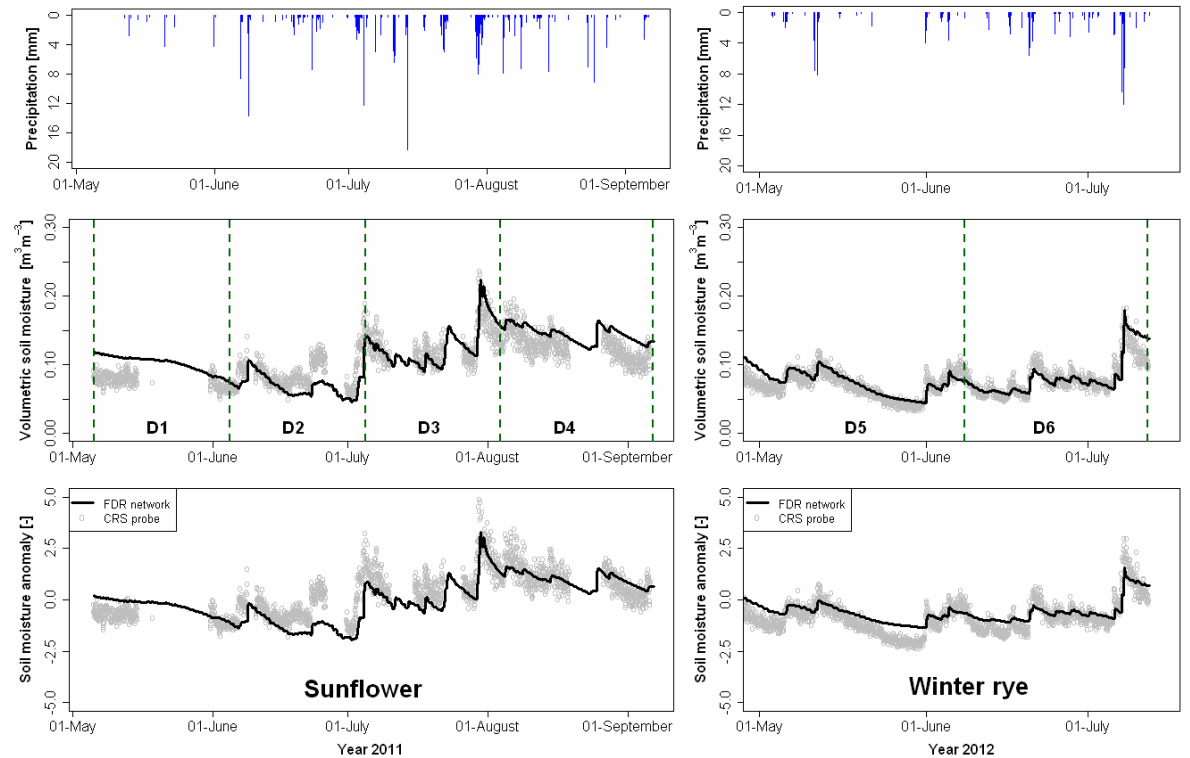

Fig. 5. Time series of soil moisture measured in the FDR network and CRS probe during the sunflower period (left side) and winter rye period (right side): hourly precipitation (upper graph), volumetric soil moisture (middle graph) and soil moisture anomalies (lower graph). FDR soil moisture corresponds to the mean value in the horizontal and vertical direction. Anomalies of soil moisture were calculated by subtracting the mean value (FDR or CRS) from the entire period and scaled to the standard deviation. Calibration periods are defined by D1-D6.
HESSD

10, 4237-4274, 2013

Soil moisture measurement in cropped fields

C. A. Rivera Villarreyes et al.

\section{Title Page}

Abstract Introduction

Conclusions

References

Tables

Figures

14

$>1$

4

Back

Close 

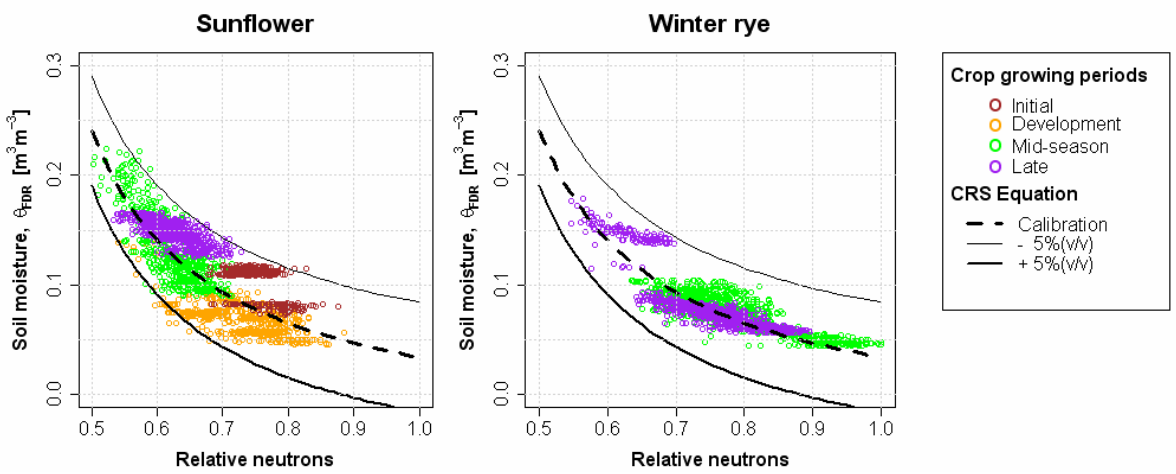

\section{HESSD}

10, 4237-4274, 2013

Soil moisture measurement in cropped fields

C. A. Rivera Villarreyes et al.

\section{Title Page}

Abstract Introduction

Conclusions References

Tables Figures

Fig. 6. Relation between FDR soil moisture and relative fast neutrons during sunflower and winter rye periods: CRS calibration is plotted as the dashed black line, and its readjustment by an increase $\left(+5 \mathrm{~m}^{3} \mathrm{~m}^{-3}\right)$ or decrease $\left(-5 \mathrm{~m}^{3} \mathrm{~m}^{-3}\right)$ of crop water content with respect to the calibration curve is plotted in continuous lines.

14

4

Back

\section{$\rightarrow 1$}

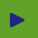

Close

Full Screen / Esc

Printer-friendly Version

Interactive Discussion 

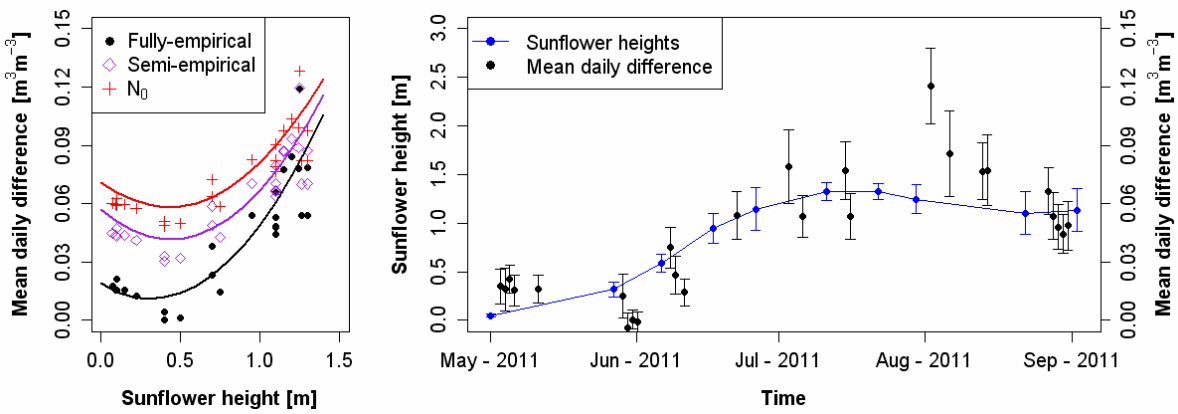

HESSD

10, 4237-4274, 2013

Soil moisture measurement in

cropped fields

C. A. Rivera Villarreyes

et al.

\section{Title Page}

Abstract Introduction

Conclusions References

Fig. 7. Influence of the vegetation season on cosmic-ray neutron sensing: correlation graph between $\Delta \theta_{\text {crop }}=\theta_{\mathrm{D} 1}-\theta_{\mathrm{D} 3}$ and sunflower heights for the three calibration approaches (left) and time series of sunflower crop height and $\Delta \theta_{\text {crop }}$ for the fully empirical approach (right). Notice that polynomial trendlines were used in the graph to the left.

Tables

14

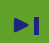

Back

Close

Full Screen / Esc

Printer-friendly Version

Interactive Discussion 


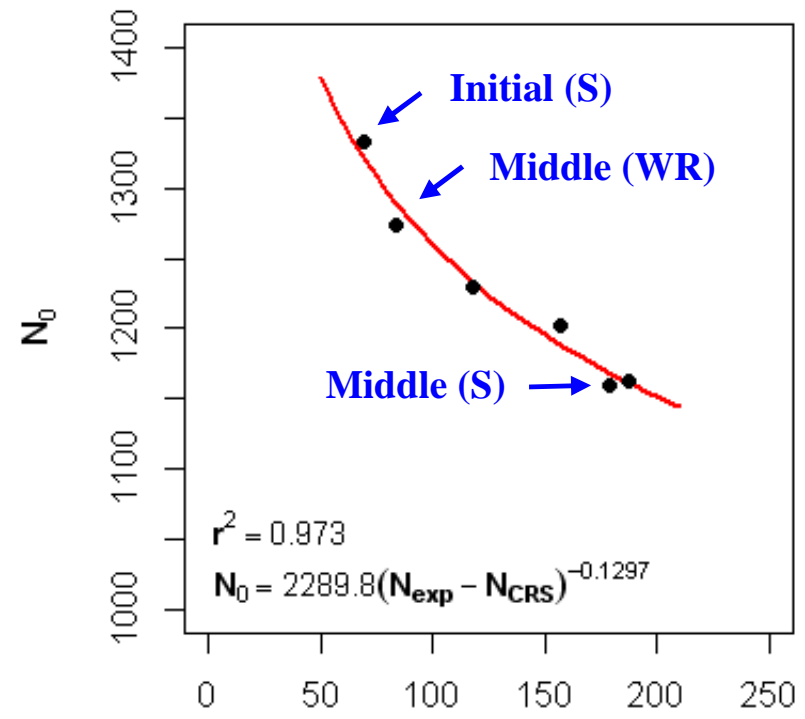

\section{Attenuated neutrons per hour}

Fig. 8. Correction of $N_{0}$ parameter from estimated value of attenuated neutrons due to additional $\mathrm{H}$ pools beside soil moisture. The $N_{0}$ values correspond to calibrated values for all datasets (D1-D6) with scenario S1. The expected neutrons without crop cover and measured neutrons are defined as $N_{\exp }$ and $N_{\text {CRS }}$, respectively. In the graph, these are the mean values for each calibration dataset. Three examples of how $N_{0}$ is correlated to the attenuated neutrons are shown for (i) initial sunflower, (ii) middle winter rye and (iii) middle sunflower in graph as Initial (S), Middle (WR) and Middle (S), respectively. We expected biomass, root density and crop water content to increase from (i) to (iii).

\section{HESSD}

10, 4237-4274, 2013

Soil moisture

measurement in

cropped fields

C. A. Rivera Villarreyes

et al.

\section{Title Page}

Abstract Introduction

Conclusions References

Tables

Figures

14

$\rightarrow$

4

Back

Close 